\title{
Poly(Methyl Methacrylate) Grafted Wheat Straw for Economical and Eco-friendly Treatment of Oily Wastewater.
}

\section{Kavya Suresh}

University of Alberta

Muhammad Amirul Islam

University of Alberta

Masoud Rastgar

University of Alberta

Brian A. Fleck

University of Alberta

Mohtada Sadrzadeh ( $\nabla$ sadrzade@ualberta.ca )

University of Alberta

\section{Research Article}

Keywords: Oily wastewater treatment, Adsorption, Wheat straw, Poly(methyl methacrylate), Free radical graft polymerization, Adsorption kinetics

Posted Date: October 28th, 2021

DOI: https://doi.org/10.21203/rs.3.rs-1013520/v1

License: (c) (1) This work is licensed under a Creative Commons Attribution 4.0 International License.

Read Full License

Version of Record: A version of this preprint was published at Cellulose on February 27th, 2022. See the published version at https://doi.org/10.1007/s10570-022-04481-1. 


\title{
1 Poly(methyl methacrylate) grafted wheat straw for economical and eco- 2 friendly treatment of oily wastewater.
}

\author{
Kavya Suresh, Muhammad Amirul Islam*, Masoud Rastgar, Brian A. Fleck, Mohtada Sadrzadeh* \\ Department of Mechanical Engineering, 10-367 Donadeo Innovation Centre for Engineering, \\ University of Alberta, Edmonton, AB, T6G 1H9, Canada.
}

\section{Abstract}

The sustainable development of oil-gas and petrochemical industries necessitates the development of cost-effective and eco-friendly technologies to treat mass-produced oily wastewater discharge from these industries. This study applied a simple radical polymerization to enhance the oil adsorption efficiency of agricultural waste biomass wheat straw (WS) by grafting biocompatible PMMA. Diesel oil adsorption from oil-in-water emulsion using the PMMA grafted WS was thoroughly studied for the first time in the quest of developing an economical and eco-friendly adsorbent for the adsorptive treatment of oily wastewater. Initially, the pristine WS was subjected to alkaline hydrogen peroxide pre-treatment to remove the materials that can lead to secondary pollution during operation, to expose the reactive cellulose surface sites that can enhance grafting efficiency, and to break the inner interconnected tubular pore channel walls; otherwise, the tubular pore channels will not be accessible to viscous oil due to limited capillary penetration. The success of pre-treatment of pristine WS and the subsequent PMMA grafting were evaluated by SEM morphology, BET analysis, EDX and XPS elemental analysis, FTIR, and contact angle measurements. SEM images indicated that the inner interconnected tubular pore channels of WS are exposed significantly upon alkaline hydrogen peroxide pretreatment. PMMA grafting substantially improved oil adhesivity, as evident from the $0^{\circ}$ oil contact angle for WS-g-PMMA film. Oil absorptivity was thoroughly evaluated by batch oil adsorption study using variable adsorbent dosages and oil emulsion concentrations. The WS-g-PMMA exhibited explicitly higher adsorption capacity ( $c a .1129 \mathrm{mg} / \mathrm{g}$ ) compared to that of the pristine ( $c a .346 \mathrm{mg} / \mathrm{g}$ ) and pretreated (ca. $741 \mathrm{mg} / \mathrm{g}$ ) due to high accessibility to exposed inner interconnected tubular pore channels and strong hydrophobic interactions between the WS-g-PMMA surface and oil droplets. Langmuir and Freundlich adsorption isotherms were applied to evaluate the adsorption mechanism. The experimental data fit well with the Freundlich isotherm, clearly indicating the heterogeneity of adsorption sites, as well as multilayer adsorption of oil. The experimental adsorption data fit well 
with the pseudo-second-order rate equation with $\mathrm{R}^{2}$ as high as 0.999 , which confirmed the

36 multilayer adsorption of oil. The high oil adsorption capacity of the WS-g-PMMA makes it a very

37 promising material for oily wastewater treatment. This will simultaneously resolve issues with the treatment of oily wastewater and facilitate the recycling of abundant quantities of waste WS. This study serves as a reference for analyzing the suitability of wheat straw for treating extremely challenging waste streams, such as SAGD produced water containing BTEX and PAHs that are also hydrophobic like diesel oil.

43 Keywords: Oily wastewater treatment; Adsorption; Wheat straw; Poly(methyl methacrylate); Free 44 radical graft polymerization; Adsorption kinetics

45

\section{Introduction}

Oily wastewater discharge from oil/gas and petrochemical industries, commonly termed as produced water, poses a substantial threat to water bodies since it often carries several toxic and carcinogenic compounds, such as benzene, toluene, ethylbenzene, and xylene known as BTEX, phenols, and polycyclic aromatic hydrocarbons (PAHs) that are harmful to aquatic fauna (Pampanin and Sydnes 2013). Industrial wastewater discharges account for approximately $10 \%$ of the total wastewater discharges. Oil and grease are common pollutants in industrial discharges, and their concentration may range from $10 \mathrm{mg} / \mathrm{L}$ to $50,000 \mathrm{mg} / \mathrm{L}$ in various industrial sources, including petroleum refineries and aluminum rolling mills. Therefore, developing an efficient and economic oily wastewater treatment technology is pivotal for the sustainable growth of industries (Cheryan and Rajagopalan 1998).

Adsorption is a promising treatment technique since it is simple, sustainable, and cost-effective (Al-Majed et al. 2012; Sabir 2015; Zamparas et al. 2020). It is also found to be efficient in removing free, dispersed, and emulsified oil (Ibrahim et al. 2009; Li et al. 2018). Adsorption-based techniques are also suitable for treating diluted effluents (Sokker et al. 2011; Xavier et al. 2018). The desired criteria for oil adsorbents are high hydrophobicity, oleophilicity, surface area, and porosity (Adebajo et al. 2003; Al-Majed et al. 2012; Pintor et al. 2016; Zamparas et al. 2020), which are found in commonly used adsorbents, including activated carbon, graphene, and carbon nanotubes. The most common traditional adsorbent used for oil-water separation is activated 
carbon (AC) (Pintor et al. 2016; Zamparas et al. 2020). Activated carbon systems, however, are

68 not economical and require rigorous regeneration of spent activated carbon due to their 69 microporous structure (Beall 2003; Pintor et al. 2016). Apart from that, its major drawback would 70 be the carbon footprint, as estimations show that the consumption of each $\mathrm{kg}$ of $\mathrm{AC}$ can release 71 approximately $0.7 \mathrm{~kg}$ of carbon dioxide with the embodied energy of around 70MJ (Zanoletti et al.

72 2018). Other synthetic high-performance adsorbents such as graphene-based materials and carbon 73 nanotubes are complicated and expensive to prepare (Pintor et al. 2016; Zamparas et al. 2020) and 74 are also characterized by their high carbon footprint (Ali et al. 2019) and difficulty in disposing of 75 used adsorbents.

77 In the context of exploring cheaper, environmentally benign, and low carbon-emitting adsorbents, 78 the recent trend is to utilize renewable natural materials, such as agricultural by-products, as an 79 alternative to traditional adsorbents (Al-Majed et al. 2012; Pintor et al. 2016; Zamparas et al. 2020) 80 It is undoubtedly wise to develop processes that can resolve diverse issues at the same time. One 81 such process development would be utilizing a waste by-product to treat another waste since it 82 would simultaneously resolve the challenges of waste management involved in both cases. The 83 spent biomass can also be easily regenerated and reused by washing with solvents with high 84 solubility for oil (Lin et al. 2003; El-Naas et al. 2010). Agricultural wastes used as adsorbents for 85 treating hydrocarbon-containing effluents include rice husk (Kudaybergenov et al. 2015), wheat 86 straw (Sun et al. 2004; Lv et al. 2017), cotton fiber (Deschamps et al. 2003), Platanus Fruit Fibers 87 (Yang et al. 2016), kapok fiber (Wang et al. 2012), and banana peels (Alaa El-Din et al. 2017). Among the variant of natural bio-adsorbents, wheat straw is unique due to its highest abundance, 90 relatively higher structural stiffness, and well-studied chemical structure and surface reactivity 91 (Liu et al. 2005). The surface of the biomasses needs to be engineered to increase their adsorptive 92 capacity (Adebajo et al. 2003). These materials can also result in secondary pollution by releasing 93 their constituent organic compounds when used in pristine form (Ibrahim et al. 2009). Therefore, 94 it is necessary to explore simple chemical modification methods that can enhance the oil 95 absorptivity and prevent secondary pollution while retaining cost-effectiveness and 96 biodegradability. Many reports have appeared on utilizing chemically surface-modified various 97 types of straw for oil adsorption (Sun et al. 2002, 2004; Ibrahim et al. 2009, 2012; Li et al. 2013; 
Lv et al. 2017; Tang et al. 2018; Xu et al. 2018). Some of the common surface modification

99 methods applied on straw include surfactant modification of barley straw (Ibrahim et al. 2009, 2012), acetylation of rice straw (Sun et al. 2002), wheat straw (Sun et al. 2004; Lv et al. 2017), and corn straw (Li et al. 2013), esterification of wheat straw with palmitic acid (Tang et al. 2018), and impregnation of silica $\left(\mathrm{SiO}_{2}\right)$ and $\mathrm{ZnO}$ particles by octyltriethoxysilane or heptadecafluorodecylalkyl trimethoxysilane coupling agents on corn straw fiber surface (Zang et al. 2016; Xu et al. 2018). As expected, the primary objective of such chemical modifications was to increase oil adsorption by increasing the surface hydrophobicity, oleophilicity, surface area, and/or porosity. The surfactant modification is based on the electrostatic interaction of cationic ends of the surfactants and the negatively charged sites on the adsorbent surface, leaving the surfactants susceptible to leaching into the treated water. Meanwhile, the acetylation (Sun et al. 2002, 2004; Li et al. 2013; Lv et al. 2017), esterification of wheat straw with palmitic acid (Tang et al. 2018), and silane coupling (Zang et al. 2016; Xu et al. 2018) reactions form ester and silyloxy bonds.

111 These bonds are susceptible to hydrolysis under acidic or basic $\mathrm{pH}$, making these surface modifications undesirable for the long-term treatment of alkaline oily wastewater, such as oil-gas produced water having $\mathrm{pH}$ in the range of 9-11. These reactions also involve excessive use of chemicals and/or multistep pre-treatment. The fluoro-silane modification for the $\mathrm{SiO}_{2}$

115 impregnation approach also alters the biodegradability of straw, and the use of halogenated compounds should be avoided since these are deleterious for the atmosphere. In this context, it is

117 important to explore surface modification methods that can retain the economic and environmental 118 benefits of using waste biomass as an adsorbent.

Polymer grafting by free radical polymerization is one such technique. It does not involve a 121 complicated process like esterification, acetylation, and silyation. In addition, polymer grafting 122 also helps in retaining the unique properties of crystalline cellulose, which would otherwise be 123 wrecked in other processes (Samal et al. 1986; Kim et al. 2020). However, free-radical mediated 124 polymer grafting is scarcely explored for the modification of lignocellulosic biomasses, such as 125 wheat straw (Russell 2002). Poly(methyl methacrylate) (PMMA) is an extensively used polymer 126 for incorporating hydrophobic properties into a wide variety of materials, including cellulose 127 (Rosli et al. 2015), wood (Fu et al. 2012), natural fibre (Chen et al. 2009), cotton fabric (Wang et 128 al. 2020), multiwalled carbon nanotubes (nan Shen et al. 2013), and inorganic nanoparticles 
129 (Huang et al. 2009; Wang et al. 2011; Soleimani and Moghaddami 2018). Apart from the high 130 hydrophobicity and oleophilicity, PMMA possesses high mechanical stability, chemical stability, 131 thermal stability, resistance to acid/base hydrolysis, biocompatibility, and reasonable 132 biodegradability (Hollick et al.; Yang et al. 2005; Alemdar et al. 2007; Maiti et al. 2013). PMMA 133 grafted wheat straw has previously been used to increase flame retardancy (Mukherjee et al. 2017) 134 and moisture resistance of straw biomasses (Thakur et al. 2013a, b). PMMA indeed has been 135 shown to enhance the oil adsorptivity of natural rubber foam (Ratcha et al. 2014, 2015). Despite 136 favorable criteria for large-scale oil adsorption treatment, PMMA grafted wheat straw (WS-g137 PMMA) was not utilized for adsorbing oil from an oil-in-water emulsion.

139 This study is the first attempt to understand the potential of WS-g-PMMA for adsorptive removal 140 oil from an oil-in-water emulsion in a systematic way through batch adsorption studies. At first, 141 the raw dried straw was mechanically ground into $250-425 \mu \mathrm{m}$ size particles. Then, the straw was 142 subjected to single-step pre-treatment with environmentally benign alkaline hydrogen peroxide $143\left(\mathrm{H}_{2} \mathrm{O}_{2}\right)$ to remove the constituents causing secondary pollution of water (wax and resins), to break 144 the lignin shield for exposing reactive hydroxyl groups for PMMA grafting, and to break the inner 145 interconnected tubular pore channel walls for allowing the access to oil. Afterward, a simple and 146 efficient radical polymerization was applied to graft PMMA on the pretreated wheat straw. Cerium 147 Ammonium Nitrate (CAN) was chosen as the reaction initiator to graft polymers predominantly 148 on the surface and to simplify the modification reaction. The success of PMMA grafting was 149 assessed by attenuated total reflection-Fourier transform infrared (ATR-FTIR) spectroscopy, 150 Energy-dispersive X-ray (EDX) spectroscopy, X-ray photoelectron spectroscopy (XPS). The 151 percentage of PMMA grafting was evaluated by gravimetric analysis. Surface morphology was 152 evaluated by scanning electron microscopy (SEM). Surface area and porosity were evaluated by 153 BET analysis. Surface wettability was analyzed by water and oil contact angle measurements, 154 while oil removal efficiency and adsorption capacity were systematically studied by batch oil 155 adsorption experiments. Langmuir and Freundlich isotherms were applied to understand the 156 adsorption mechanism. Finally, adsorption kinetics was studied by applying pseudo-first-order and 157 pseudo-second-order kinetic models. 


\section{Experimental Method}

\subsection{Materials and Chemicals}

162 Wheat straw was obtained from a farm in the Edmonton area. Methyl methacrylate (MMA) (99\%), cerium ammonium nitrate ( $\geq 98 \%$ ), and nitric acid were all obtained from Sigma Aldrich and were used as received. Acetone and methanol used for the purification of grafted material were purchased from Fisher Scientific. Ethanol (95\%) was used for regenerating the spent column and was procured from Fisher Scientific. Sodium hydroxide pellets and hydrogen peroxide (30\%) used

167 for the pre-treatment of straw particles prior to grafting were purchased from Fisher Scientific. 168 Diesel oil was obtained from a local fuel station.

\subsection{Pre-treatment of wheat straw}

171 Wheat straw was pulverized and sieved through 60 and 80 mesh screens to obtain particles in size 172 range of $250-425 \mu \mathrm{m}$. The particles were rinsed ultrasonically with deionized (DI) water, followed

173 by ethanol and DI water washing. The particles were then subjected to pre-treatment with $\mathrm{NaOH}$ 174 and $\mathrm{H}_{2} \mathrm{O}_{2}$ to break the lignin shield enclosing the cell wall. Each $4 \mathrm{~g}$ of wheat straw particles was 175 treated with $100 \mathrm{~mL}$ of $0.5 \mathrm{wt} \% \mathrm{NaOH}$ and $3.5 \mathrm{~mL}$ of $30 \% \mathrm{H}_{2} \mathrm{O}_{2}$ (Xu et al. 2018). The solution was

176 stirred for $14 \mathrm{~h}$ at ambient temperature. The unreacted reagents and by-products were removed by 177 rinsing the pretreated particles thoroughly with DI water and ethanol. Any excess alkaline residue 178 in the solution was neutralized by adjusting the $\mathrm{pH}$ in the range of $6.5-7.0 \mathrm{using} 6 \mathrm{~mol} / \mathrm{L} \mathrm{HCl}$. At 179 last, the pretreated particles were rinsed thoroughly with DI water and dried at $40{ }^{\circ} \mathrm{C}$ until a 180 constant weight was reached.

\subsection{Preparation of WS-g-PMMA}

183 The pretreated wheat straw was dispersed in a fixed volume of DI water. The volume of DI water 184 was optimized during the initial reactions with the intention of keeping the amount of solvent as 185 low as possible, just sufficient to disperse the straw particles. Optimizing the amount of solvent 186 also helped in maintaining the good miscibility of all the reagents, providing favorable reaction 187 kinetics, and facilitating the precipitation of PMMA grafted particles from the reaction mixture. 188 Hence, a preliminary visual interpretation of the success of the reaction was achieved. The 189 dispersion was stirred at $70{ }^{\circ} \mathrm{C}$ for $1 \mathrm{~h}$ under a nitrogen atmosphere. Following that, MMA was 
190

191

192

193

194

195

196

197

198

199

200

201

202

203

204

205

206

207

208

209

210

211

212

213

214

215

216

217

218

219

added dropwise using a syringe over a $30 \mathrm{~min}$ period while stirring the reaction mixture at 350 rpm. Finally, $10 \mathrm{~mL}$ of $2 \mathrm{mmol} / \mathrm{L}$ of CAN solution, prepared by dissolving CAN in $0.1 \mathrm{~mol} / \mathrm{L}$ nitric acid, was added to the mixture, and stirred under the nitrogen atmosphere for $1 \mathrm{~h}$. The weight ratio of WS/MMA was varied from 0.75 to 3.65 to optimize the amount of MMA required for the effective grafting of PMMA. The mixture was cooled to room temperature, and the grafting was terminated by pouring the mixture into excess methanol solution, followed by washing the precipitated WS-g-PMMA granules with DI water. The grafted particles were then dried at $40{ }^{\circ} \mathrm{C}$ until a constant weight was reached. The ungrafted homopolymer was extracted using acetone in a Soxhlet apparatus. The extracted sample was dried at $40{ }^{\circ} \mathrm{C}$ for $24 \mathrm{~h}$. The grafting percentage (GP) was calculated as (Fakhru'L-Razi et al. 2001):

$$
\mathrm{GP}=\frac{\mathrm{W}_{2}-\mathrm{W}_{1}}{\mathrm{~W}_{1}} \times 100
$$

where $W_{l}$ is the initial weight of wheat straw particles in $\mathrm{g}$, and $W_{2}$ is the weight of WS-g-

PMMA particles in $\mathrm{g}$.

\subsection{Characterization of WS-g-PMMA}

The grafting of PMMA was evaluated by comparing the ATR-FTIR (Bruker, Equinox 55) frequencies and high-resolution C1s XPS (Kratos AXIS Ultra) spectra of WS-g-PMMA with that of pristine and pretreated WS. The surface morphology was analyzed by scanning electron microscopy (SEM) (FE-SEM, Zeiss, Oberkochen, Germany), and the elemental composition was determined by Energy-dispersive X-ray (EDX) (Bruker model) spectroscopy. Information on porosity and surface area were obtained by Brunauer-Emmett-Teller (BET) and Density Functional Theory (DFT) analysis by outgassing the samples with nitrogen at $150{ }^{\circ} \mathrm{C}$ for $2 \mathrm{~h}$ in physisorption/chemisorption analyzers (Quantachrome Autosorb iQ). The wettability of the samples was analyzed by measuring contact angles by the sessile drop method (Kruss $\mathrm{GmbH}$ ). The wheat straw samples were pressed and compacted using an FTIR pellet press at room temperature to obtain pellets with approximately $5 \mathrm{~mm}$ diameter (Guettler et al. 2013). The pellets were firmly fixed on a glass side using double-sided tape. A $2 \mu 1$ droplet of DI water or oil (diesel) was placed on the sample surface using a syringe, and the measurements were taken at three different spots to obtain an average value. 
221 Three different concentrations (100, 200, and $300 \mathrm{ppm})$ of oil-in-water emulsions were prepared 222 by placing 100, 200, and $300 \mathrm{mg}$ of diesel in $1 \mathrm{~L}$ of DI water followed by probe sonication (Cole223 Parmer ultrasonic processor) for 15, 25, and $35 \mathrm{~min}$ respectively at $60 \%$ amplitude in pulse mode 224 (3s on and 1s off) (Diraki et al. 2018). Following that, the solutions were homogenized 225 (Fisherbrand ${ }^{\mathrm{TM}}$ 150) at 10,000 rpm for $15 \mathrm{~min}$. The stability of the emulsions was assessed by 226 visual monitoring for $24 \mathrm{~h}$. The dynamic light scattering technique (DLS, ALV/CGS-3 Compact 227 Goniometer) was used to determine the size distribution of oil droplets in the emulsion. The oil 228 emulsion of $300 \mathrm{ppm}$ concentration was found to be monodisperse with a droplet size of $0.47 \pm$ $2294.15 \mu \mathrm{m}$.

\section{2.6. Batch adsorption study}

232 Oil removal efficiency and adsorption capacity of the pristine, pretreated, and WS-g-PMMA were 233 studied by batch adsorption experiments. Three different variables considered for the adsorption 234 study were the initial oil concentration, the adsorbent dosage, and the contact time. The 235 experiments were carried out by varying the adsorbent dosage from 5 to $25 \mathrm{mg}$ for each initial oil 236 concentration of 100, 200, and 300 ppm, respectively. Centrifuge tubes with a capacity of 50mL 237 were filled with $40 \mathrm{~mL}$ of emulsion and mixed at a constant shaking speed (160 oscillations/min) 238 using a mechanical shaker (Eberbach 6000) for a total time of $1 \mathrm{~h}$. The WS-g-PMMA samples 239 were then centrifuged at $1000 \mathrm{rpm}$, and the remaining oil concentration was analyzed by measuring 240 the scattering at $290 \mathrm{~nm}$ with a UV-visible spectrophotometer. A control tube with emulsion alone 241 was also tested.

242 The adsorption capacity and oil removal efficiency were calculated using the formulas (Diraki et 243 al. 2018):

$$
\begin{aligned}
& \mathrm{q}_{\mathrm{t}}=\frac{\left(\mathrm{C}_{0}-\mathrm{C}_{\mathrm{t}}\right) \times \mathrm{V}}{\mathrm{W}_{\mathrm{g}}} \\
& \mathrm{RE}=\frac{\mathrm{C}_{0}-\mathrm{C}_{\mathrm{t}}}{\mathrm{C}_{0}} \times 100
\end{aligned}
$$

246 where $C_{0}$ is the initial oil concentration (ppm), $C_{t}$ is the oil concentration (ppm) at time $t$ after

247 adsorption on WS samples, $V$ is the volume of emulsion $(\mathrm{mL})$, and $W_{g}$ is the weight of adsorbent 248 (mg). 
251 Adsorption isotherm models were used to represent the equilibrium relationship of the adsorption 252 process graphically. It describes the amount of oil being adsorbed by the WS samples as a function 253 of adsorbent concentration at a constant temperature.

\subsubsection{Langmuir isotherm}

256 This model is mainly defined for monolayer adsorption ( $\mathrm{Xu}$ et al. 2012), where the following 257 assumptions are considered: (a) adsorption sites possess the same energy, and the number of 258 adsorption sites remains constant (homogenous surface), and (b) adsorption is reversible. 259 Therefore, at equilibrium, the rates of adsorption and desorption are assumed to be the same. The 260 linearized form of the Langmuir equation is given by:

$$
\frac{\mathrm{C}_{\mathrm{e}}}{\mathrm{q}_{\mathrm{e}}}=\frac{1}{\mathrm{q}_{0} \mathrm{~b}}+\frac{\mathrm{C}_{\mathrm{e}}}{\mathrm{q}_{\mathrm{m}}}
$$

262

where $C_{e}$ is the concentration of oil (ppm) at equilibrium, $q_{e}$ is the value of $q$ at equilibrium (mg),

$264 q_{m}$ is the mass of adsorbate adsorbed per unit mass of adsorbent (i.e., $\mathrm{mg}$ adsorbate/g adsorbent), and $b$ is an empirical constant. A plot of $C_{e} / q_{e}$ versus $C_{e}$ is used to determine the mechanism of 266 adsorption.

\subsubsection{Freundlich isotherm}

269 The Freundlich model is a more comprehensive isotherm and deals with both homogenous and 270 heterogeneous surfaces. In addition, the model applies for multilayer adsorption, i.e., physisorption 271 (Xu et al. 2012). The expression of this model is given by:

$$
\mathrm{q}_{\mathrm{e}}=\mathrm{KC}_{\mathrm{e}}^{1 / \mathrm{n}}
$$

273 where $K$ is Freundlich constant related to adsorption capacity, and $n$ is an empirical value, which

274 is a function of the degree of heterogeneity of the adsorbent. The intercept of the plot of log $q_{\mathrm{e}}$ 275 versus $\log C_{e}$ gives $K$ and $n$.

\section{2.8. Adsorption kinetics}

278 Pseudo-first order and pseudo-second-order kinetic models are widely applied to understand the

279 behaviors involved in the uptake of pollutants by adsorbents. The experimental adsorptivity data 
were obtained by varying the contact time at five-minute intervals using an initial oil concentration of $300 \mathrm{ppm}$, WS samples dosage of $5 \mathrm{mg}$, and shaking speed of 160 oscillations/min and were analyzed by plotting a linear fit. The pseudo-first-order kinetic equation in linear form is given by (Diraki et al. 2018):

$$
\ln \left(\mathrm{q}_{\mathrm{e}}-\mathrm{q}_{\mathrm{t}}\right)=\ln \mathrm{q}_{\mathrm{e}}-\mathrm{k}_{1} \mathrm{t}
$$

where $q_{t}$ is adsorption capacity at time $t(\mathrm{mg} / \mathrm{g}), k_{l}$ is the pseudo-first-order rate constant $\left(\mathrm{min}^{-1}\right)$. The plot of $\ln \left(q_{e}-q_{t}\right)$ versus $t$ was used to determine $k_{l}$.

287 The pseudo-second-order kinetic equation in linear form is given by:

$$
\frac{\mathrm{t}}{\mathrm{q}_{\mathrm{t}}}=\frac{1}{\mathrm{k}_{2} \mathrm{q}_{\mathrm{e}}^{2}}+\frac{\mathrm{t}}{\mathrm{q}_{\mathrm{e}}}
$$

where $k_{2}$ is the pseudo-second-order rate constant (g/mg min). A linear fit of $t / q_{t}$ versus $t$ was applied to obtain $k_{2}$ and $q_{e}$ from intercept and slope, respectively.

\section{Results and Discussion}

\subsection{Pre-treatment of pristine WS and PMMA grafting via radical initiated polymerization}

The mechanism of grafting with ceric ion $\left(\mathrm{Ce}^{4+}\right)$ as initiator involves the formation of an intermediate complex with the cellulosic units and results in a macro-cellulosic short-lived radical on either carbon $\mathrm{C}_{2}$ or carbon $\mathrm{C}_{3}$ or the hydroxyl groups bonded to these carbons of cellulose backbone (Figure 1) (Tosh and Routray 2014). The polymeric chains will be incorporated onto the cellulose backbone at these active sites resulting in the formation of the graft copolymer. The propagation of the polymeric chain will be initiated by a reaction between the macro-cellulosic radical and the monomer. The reaction terminates when the polymeric radicals react among themselves or react with $\mathrm{Ce}^{3+}$, resulting in the regeneration of active $\mathrm{Ce}^{4+}$ species. However, the fibrous cellulose in the WS cell wall needs to be exposed using a pre-treatment process. Moreover, pre-treatment is also necessary to increase the surface roughness by removing lignin and hemicellulose intercalated between cellulose fibers. Overall, the alkaline treatment solubilizes lignin and subsequently swells the cell wall and cellulose microfibrils (Thomsen et al. 2021). This step is crucial to gain access to cellulose which is present in the crux of the cell wall (Brandt et al. 2013; Williams et al. 2019). In addition to augmenting the grafting of PMMA on cellulose, the chemical treatment also serves the purpose of having extractive-free biomass, which makes sure 
310 that there will be no secondary pollution of water. It also opens the tubular interconnected pore 311 channels, which otherwise will not be accessible to viscous oil during oil adsorption. A simple 312 one-step economical and environmentally benign pre-treatment of WS, using a mixture of $0.5 \mathrm{wt} \%$ $313 \mathrm{NaOH}$ and $30 \% \mathrm{H}_{2} \mathrm{O}_{2}$, is shown to be effective in serving all the purposes described above [29]. 314 Figure 1 shows pre-treatment derived degradation of cell walls, exposure of internal cellulose 315 fibers, and extraction of lignin and hemicellulose (Zang et al. 2016).
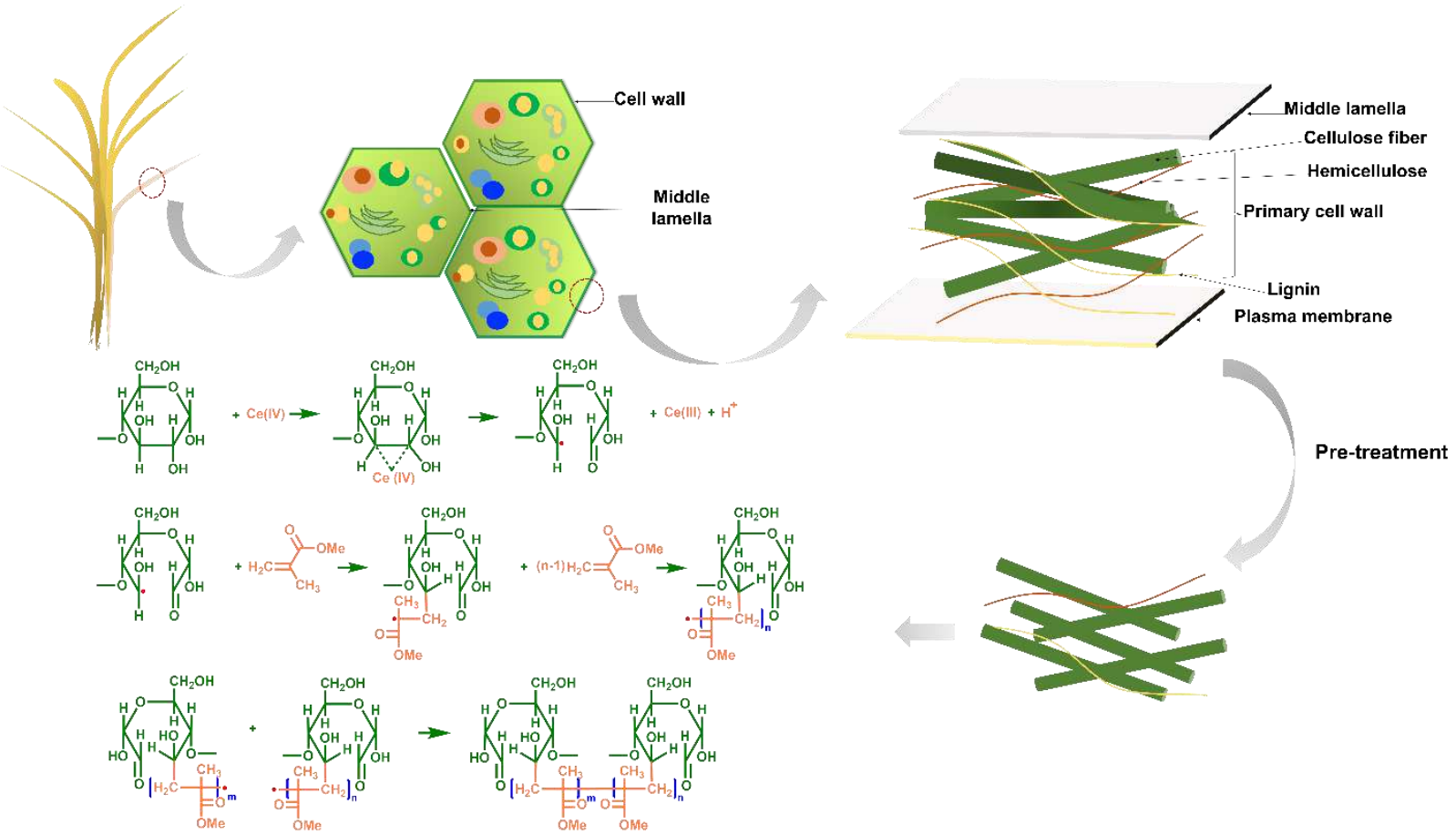

Figure 1. Structure of lignocellulosic WS, the pre-treatment process to expose the embedded fibrous cellulose, and mechanism of graft copolymerization of PMMA on the exposed fibrous cellulose.

321 The significant parameters that influence the grafting percentage (Gp) include reaction time,

322 initiator concentration, monomer concentration, and reaction temperature. Many researchers have

323 extensively studied the effect of these parameters on the efficiency of CAN-initiated

324 polymerization. Therefore, reaction time, temperature, and initiator concentration were chosen

325 from previous literature (Fakhrul-Razi et al. 2009), and this study focused on the effects of

326 monomer concentration on the grafting percentage of PMMA since the objective was to use a

327 minimum amount of monomer to enhance the cost-efficiency of straw modification. Moreover,

328 monomer concentration is the predominant parameter that defines the graft percentage of CAN 
initiated polymerization. The concentration of monomer significantly affects the dilution of macrocellulosic radical sites, miscibility of the reagents, viscosity of the reaction medium, and availability of the monomers in the vicinity of macro-cellulosic radicals. The weight ratio of WS/MMA varied from 0.75 to 3.65 , and the highest graft percentage of $127 \%$ was obtained for the WS/MMA ratio of 1.25. The increase in the monomer amount from $2.4 \mathrm{~g}$ of MMA to $4.7 \mathrm{~g}$ and then to $7.5 \mathrm{~g}$ increased the graft percentage of PMMA from $103 \%$ to $118 \%$ and then $127 \%$. However, a further increase in the monomer concentration up to $12.5 \mathrm{~g}$ caused a downfall in the PMMA graft percentage to $109 \%$. This lowering in the percentage of grafting at high monomer concentration is presumably associated with the dilution of the WS, increased phase separation between the solvent water and monomer, or the higher viscosity of the reaction medium that ultimately slows down the diffusion of the monomer to the active sites. The WS with the highest PMMA grafting percentage of $127 \%$ was used for all characterization and oil adsorption studies.

\subsection{Characterisation of adsorbents}

\subsubsection{Morphology and elemental analysis of pristine, pretreated and WS-g-PMMA} The SEM micrographs (Figure 2) display the distinctive fibrous microstructures and the surface morphology of the pristine, pretreated, and PMMA grafted wheat straw. At lower magnifications (Figure 2 top panels), the structure of the pristine, pretreated WS looked similar, but the structure of WS-g-PMMA was broken to some extent. This indicated that the overall original structure of wheat straw was not changed dramatically. The micrographs at higher magnifications (Figure 2 middle panels) clearly displayed the differences between the three samples. While the pristine straw exhibited a homogenous, smooth surface with a hollow tubular structure, the pretreated straw sample exhibited a loose and fibrous structure with a porous structure opened along the pore walls.

354 transport of water; these pores are, therefore, not accessible to oil due to limited capillary penetration and need to be opened from the sides of the pore walls to allow access to oil. The PMMA grafted WS samples exhibited an undulant coarse surface and a mesh-like texture among 357 smoother domains of PMMA, indicating the presence of a percolating network. Similar observations were reported for grafting PMMA on Agave Americana fibers (Singha and Rana 2012). In addition, the magnified SEM image of WS-g-PMMA clearly shows that they are 
360 composed of numerous bridging fibrils which conduct water through the plant body. The 361 microporous structure of WS-g-PMMA is also showcased by the profuse vessel to vessel pitting 362 (Jiang et al. 2018). Smaller sizes of WS-g-PMMA particles, the formation of a percolating 363 network, and exposed vessels, as well as the vessel to vessel pitting, are all beneficial for enhanced 364 oil adsorption. The elemental composition of pristine, pretreated, and WS-g-PMMA is evaluated 365 by EDX analyses (Figure 2 bottom panels). The main elements existing in the pristine WS are 366 carbon $(\mathrm{C}, 35.2 \%)$, oxygen $(\mathrm{O}, 47.1 \%)$, and silicon $(\mathrm{Si}, 17.7 \%)$. Carbon and oxygen originate from 367 basic compositional polymers (i.e., cellulose, hemicellulose, and lignin) of WS as well as the wax 368 and resins of the cell walls. Meanwhile, silicon originates from the abundant silica in the plant cell 369 walls accumulated by the absorption of silicon from the soil (Dodson 2011; Abd-Talib et al. 2018). 370 Silica also contributes to the high percentage oxygen content in the elemental composition of 371 pristine WS. In contrast to the pristine straw, the percentage of silicon is negligible in pretreated 372 straw. This indicated that the alkaline hydrogen peroxide pre-treatment successfully removed the 373 silica from the cell wall, almost completely leaving behind empty cavities, which are essential for 374 higher oil adsorption capacity (Dodson 2011). Moreover, the C/O ratio in the pretreated WS is 375 1.14, which is almost twice compared to pristine WS (0.75) and very close to the C/O ratio of 1.2 376 in cellulosic repeating units. Note that the low $\mathrm{C} / \mathrm{O}$ ratio in pristine WS is related to the high 377 amount of oxygen originating from silica in addition to the oxygen in the basic compositional 378 polymers of WS and cell wall matrix. This means that alkaline hydrogen peroxide pre-treatment 379 effectively removed most of the wax, resins, silica, lignin, and hemicellulose, mostly leaving 380 behind the cellulosic fibrous structure. The removal of these materials is essential for eliminating 381 the materials responsible for secondary pollution, exposing the reactive surface sites for PMMA 382 grafting, and increasing the access for oil adsorption. 

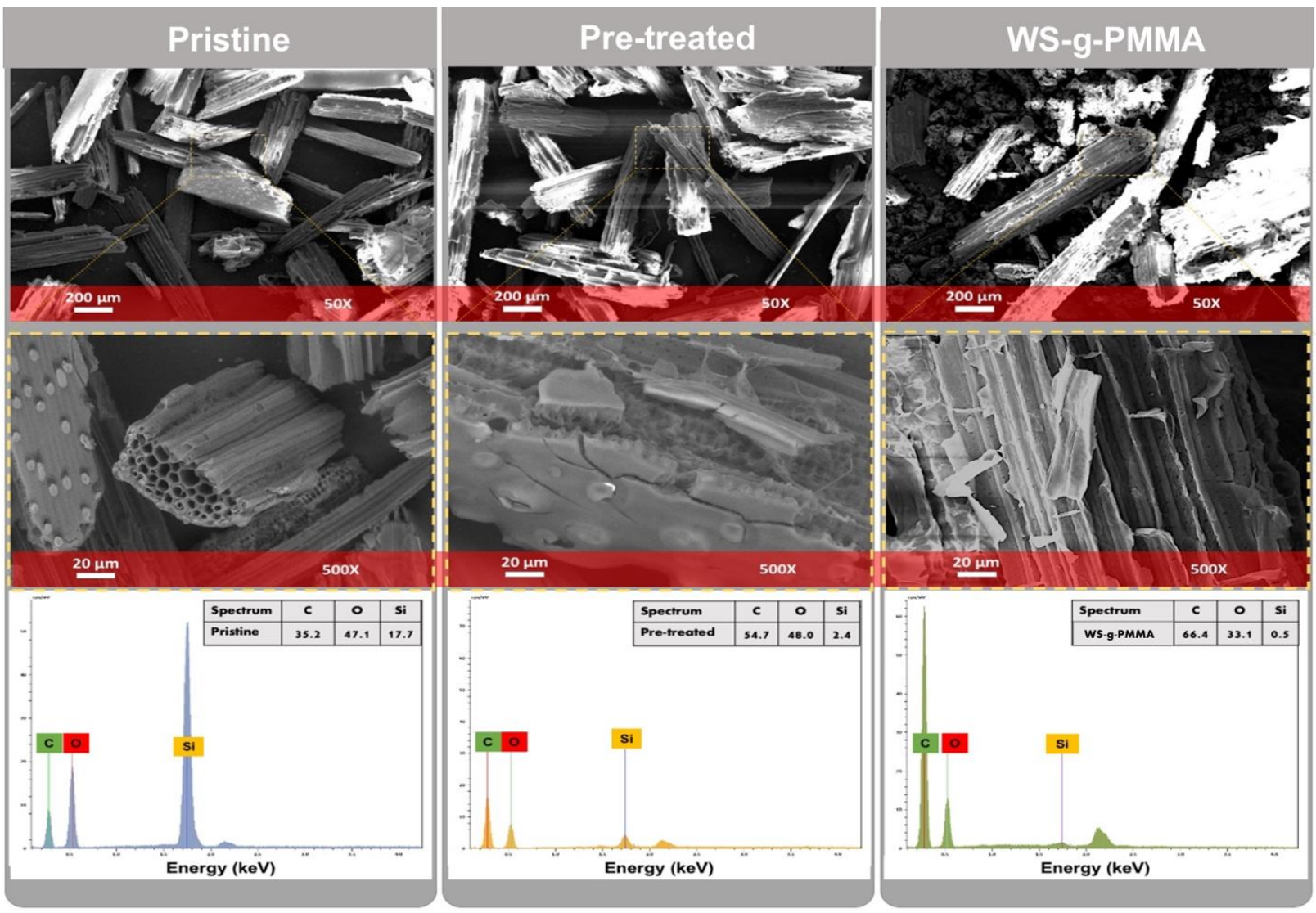

Figure 2. SEM micrographs at lower and higher magnifications, and EDX results of pristine, pretreated, and WS-gPMMA. The hollow tubular structure of the pristine WS and porous structure with broken surface roughness and loose fibers of pretreated WS are easily visible. The WS-g-PMMA sample possessed vessels with numerous micropores.

388 Meanwhile, the C/O ratio in the WS-g-PMMA was twice that in the pretreated WS, indicating considerable grafting of PMMA onto the fibrous cellulose backbone. The efficient grafting of PMMA is highly essential for the hydrophobization of fibrous cellulose and the increase in oil adsorption capacity. The observation related to the changes in elemental composition upon PMMA grafting is consistent with a previous study in which PMMA grafted rice straw has been used as a roofing material (Mukherjee et al. 2017). The intensity of the $\mathrm{C}$ atom bonded to $\mathrm{O}(\mathrm{C}-\mathrm{O}$, and $\mathrm{C}=\mathrm{O})$ over the $\mathrm{C}$ atom bonded $\mathrm{C}(\mathrm{C}-\mathrm{C})$ in the XPS $\mathrm{C} 1$ s region increased from pristine to pretreated to WS-g-PMMA (Figure 3), indicating the progress of each step of pre-treatment and PMMA grafting. The $\mathrm{C}-\mathrm{C}$ bonded $\mathrm{C}$ arises from alkyl and aryl groups, $\mathrm{C}-\mathrm{O}$ bonded $\mathrm{C}$ arises from the ether, alcoholic, and carbonyl functional groups, and $\mathrm{C}=\mathrm{O}$ arises from only carbonyl functional groups (Yu et al. 2007). Pre-treatment removes carbon-rich waxes, resins, and lignin, leaving mostly oxygen-rich cellulose in addition to some hemicellulose. Therefore, the intensity of the C-O peak and the corresponding $\mathrm{C}-\mathrm{O} / \mathrm{C}-\mathrm{C}$ increases upon pre-treatment. Meanwhile, PMMA grafting 
401 increases the $\mathrm{C}-\mathrm{O}$ bonded $\mathrm{C}$ from its ester carbonyl groups leading to the increase in the intensity 402 of this $\mathrm{C}-\mathrm{O}$ peak and the corresponding $\mathrm{C}-\mathrm{O} / \mathrm{C}-\mathrm{C}$. The trend of the $\mathrm{C}=\mathrm{O} / \mathrm{C}-\mathrm{O}$ is more obvious in 403 realizing the progress of the pre-treatment and the PMMA grafting. The pristine WS contain more 404 carbonyl carbon originating from the waxes, lignin, and hemicellulose. Removal of these 405 constituents reduces the carbonyl $\mathrm{C}=\mathrm{O}$ bond contents the pretreated WS. Therefore, the $\mathrm{C}=\mathrm{O} / \mathrm{C}-\mathrm{O}$ 406 for pretreated WS is lower than that for pristine WS. On the other hand, $\mathrm{C}=\mathrm{O} / \mathrm{C}-\mathrm{O}$ increases from 407 pretreated WS to WS-g-PMMA since the ester functional groups of PMMA are adding more $\mathrm{C}=\mathrm{O}$ 408 bonds.

409
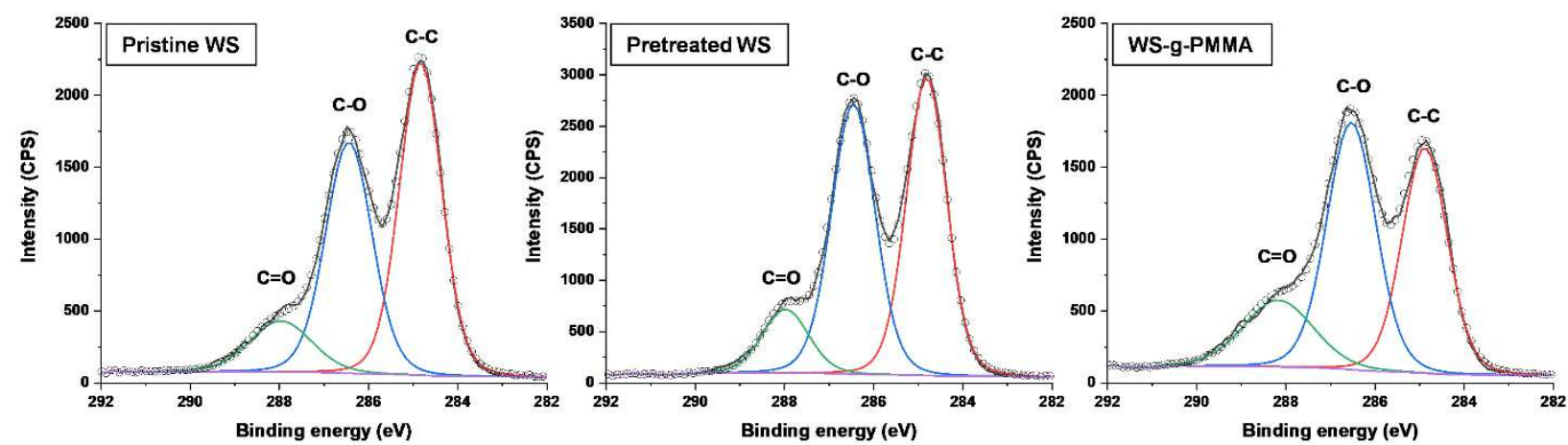

\begin{tabular}{lcccccc}
\hline Sample & $\mathrm{C}-\mathrm{C}($ atom $\%)$ & $\mathrm{C}-\mathrm{O}($ atom $\%)$ & $\mathrm{C}=\mathrm{O}($ atom $\%)$ & $\mathrm{C}-\mathrm{O} / \mathrm{C}-\mathrm{C}$ & $\mathrm{C}=\mathrm{O} / \mathrm{C}-\mathrm{C}$ & $\mathrm{C}=\mathrm{O} / \mathrm{C}-\mathrm{O}$ \\
\hline Pristine WS & 48.72 & 39.65 & 11.72 & 0.81 & 0.24 & 0.30 \\
Pretreated WS & 44.83 & 44.13 & 11.04 & 0.98 & 0.25 & 0.25 \\
WS-g-PMMA & 37.95 & 44.81 & 17.24 & 1.18 & 0.45 & 0.38 \\
\hline
\end{tabular}

Figure 3. XPS C1s regions, demonstrating the increase in the intensity of the $\mathrm{C}$ atom bonded to $\mathrm{O}(\mathrm{C}-\mathrm{O}$, and $\mathrm{C}=\mathrm{O})$ over $\mathrm{C}$ atom bonded $\mathrm{C}(\mathrm{C}-\mathrm{C})$ for pristine to pretreated to WS-g-PMMA. The corresponding table shows the atomic percentage of $\mathrm{C}$ in different bonding environments and the ratio of $\mathrm{C}-\mathrm{O} / \mathrm{C}-\mathrm{C}, \mathrm{C}=\mathrm{O} / \mathrm{C}-\mathrm{C}$, and $\mathrm{C}=\mathrm{O} / \mathrm{C}-\mathrm{O}$.

\subsection{2. surface functional groups of pristine, pretreated and WS-g-PMMA}

416 The success of pre-treatment and subsequent PMMA grafting was evaluated by the simultaneous

417 disappearance of characteristic vibration modes of pristine WS and appearance of characteristics 418 PMMA vibration modes in the FTIR spectrum of pretreated WS and WS-g-PMMA, respectively 419 (Figure 4). The carbonyl $(\mathrm{C}=\mathrm{O})$ stretching vibration due to the carbonyl groups of wax, 420 hemicellulose, and lignin around $1730 \mathrm{~cm}^{-1}$ in pristine straw is almost absent in pretreated straw.

421 This can be attributed to the extraction of wax, hemicellulose, and lignin during pre-treatment (Lv 422 et al. 2017). A dominant peak at $1035 \mathrm{~cm}^{-1}$ is for the $\mathrm{C}-\mathrm{O}$ stretching vibration of the C-O-C ether 423 linkage and C-O-H bonds, and the second dominant peak in between $3000-3600 \mathrm{~cm}^{-1}$ is for the O- 
$424 \mathrm{H}$ stretching vibrations of the hydroxyl groups of cellulose, hemicellulose, and lignin present in 425 pristine WS. The intensity of these peaks became more pronounced in the FTIR spectrum of 426 pretreated WS, further supporting the inference that pre-treatment removed other species (e.g., 427 lignin and hemicellulose), leaving behind predominantly the cellulose fibrous structure. Note that 428 cellulose units contain more $\mathrm{OH}$ functional groups and ether linkages than those present in lignin 429 and hemicellulose. Lastly, the intensity of the hydroxyl group's peak declined significantly after 430 the grafting of PMMA on the pretreated sample due to the hydroxyl groups' participation in radical 431 creation that reacted with the monomer and was subsequently replaced by PMMA. Moreover, the 432 evolution of new prominent peaks centered at 1720 and $1147 \mathrm{~cm}^{-1}$ can be attributed to $\mathrm{C}=\mathrm{O}$ and 433 C-O stretching vibration modes of the ester groups, respectively, which are characteristic vibration 434 modes of PMMA (Sugumaran et al. 2017; Galhardo et al. 2018) and confirm the success of PMMA 435 grafting.

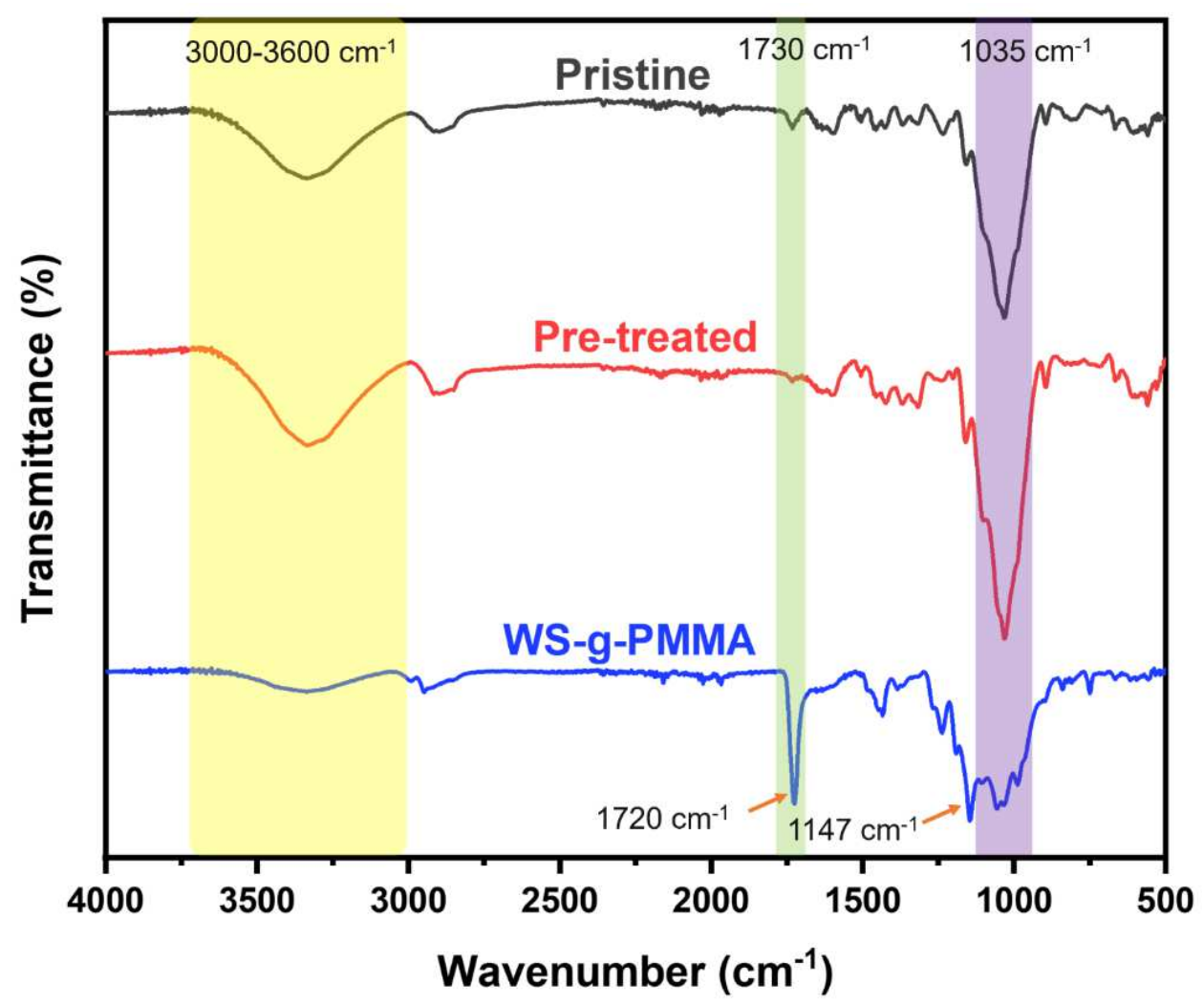

437 Figure 4. FTIR spectra of pristine WS, pretreated WS, and WS-g-PMMA. 
440 The surface area of the pristine, pretreated, and WS-g-PMMA was analyzed using Brunauer441 Emmett-Teller (BET) theory, and pore size distribution was analyzed with DFT (Density 442 Functional Theory) by outgassing the samples with nitrogen at $150{ }^{\circ} \mathrm{C}$ for $2 \mathrm{~h}$ (Quantachrome 443 Autosorb iQ). The surface area, pore size, and pore volume of all three samples are presented in 444 Figure 5 and Table 1. The shape of the hysteresis loops in Figure 5 and the pore size (Table 1) 445 for pristine, pretreated, and WS-g-PMMA clearly indicate the presence of mesopores and 446 micropores in all three samples. However, the mesopore distribution predominates in all the 447 samples. The morphology of the materials (Figure 2 middle panels) shows a highly diverse 448 distribution of pores and hence indicates that the materials indeed consist of a complex porous 449 structure. The International Union of Pure and Applied Chemistry (IUPAC) isotherm type IV(a) 450 and (b), therefore, comes into the picture (Thommes et al. 2015). The type (IV) isotherms are 451 usually considered for materials with complex pore systems. The surface area and pore volume of 452 the samples are in the order of pristine WS > pretreated WS < WS-g-PMMA. The reason behind 453 the low surface area and pore volume of pretreated WS and WS-PMMA compared to pristine WS 454 is mainly believed to be due to the kinetic restrictions of the flow of nitrogen into their narrow 455 micropores $(<0.45 \mathrm{~nm}$ ). The shape of the hysteresis loop for pristine WS (Figure 5d) mostly 456 correlates with type H2(a) hysteresis since the desorption curve is steep (Cychosz and Thommes 457 2018), the reason being a wide distribution of pore cavity compared with the neck distribution. 458 The structure of the tubular vascular interconnected vessels (Figure 2 middle panel left) with 459 numerous pits at each node in the structure of pristine WS justifies this finding (Liu et al. 2005; 460 Yu et al. 2008). The hysteresis loop shape for pretreated and WS-g-PMMA (Figures 5e and 5f) 461 also indicate type H2(a), but with cavitation (Monson 2012). This indicated that adsorption is 462 accompanied by desorption through cavitation for smaller pore sizes at a certain critical 463 temperature. The pretreated WS and WS-g-PMMA contain numerous micropores along with 464 mesopores in contrast to the pristine WS. Hence, the micron-sized pores are causing cavitation in 465 these samples, leading to lower estimated surface area and pore volume values. Meanwhile, the 466 shape of the DFT (Figure 5d) also indicates that the pristine sample has a larger number of 467 mesopores compared to the pretreated and WS-g-PMMA.

468 The reason for a higher surface area and pore volume of the pristine WS can also be due to the 469 presence of the epidermis consisting of an increased number of the original mesopores. In this 470 circumstance, the decrease in the surface area and pore volume of pretreated WS and WS-g-PPMA 
471 can be attributed to the defragmentation of the outer layers of wheat straw, including the epidermis

472 and lignin. One important observation is that the surface area and pore volume increased from

473 pretreated WS to WS-g-PMMA. Temperature plays a major role in defining the porous structure

474 of biomass material (Daud et al. 2003; Lee et al. 2014; Quach et al. 2017). Many studies have

475 reported the increase in BET surface area and pore volume at higher reaction temperatures

476 involving steam due to expansion/coalescence of the existing micropores to form macropores and

477 also the simultaneous formation of new pores (Daud et al. 2003; Zhao et al. 2017; Ding et al.

478 2020). The temperature of the PMMA grafting reaction was $70{ }^{\circ} \mathrm{C}$, and the total residence time of

479 pretreated WS under this temperature was $2.5 \mathrm{~h}$; the prolonged duration under his temperature

480 might have contributed to the formation of new pores and enlargement of the existing ones. The

481 oxidizing environment under CAN and nitric acid might have also contributed to an increase in

482 porosity and surface area. However, nitrogen is sometimes inappropriate for analyzing micropores,

483 especially for those consisting of non-polar surfaces (e.g., PMMA grafted in this study). The

484 interaction of nitrogen with non-polar surface functionalities can lead to inaccurate surface area

485 values as these interactions may shift the pore filling pressure of nitrogen to a very low relative

486 pressure $\left(\mathrm{P} / \mathrm{P}_{\mathrm{o}}=\right.$ about $\left.10^{-7}\right)$. Hence, $\mathrm{P} / \mathrm{P}_{\mathrm{o}}$ does not correlate well with the micropore sizes in these

487 cases. Therefore, the surface area value for WS-g-PMMA might be higher than estimated with

488 nitrogen. Even if the surface area and pore volume are higher for pristine WS due to the presence

489 of interconnected tubular pore channels and these channels are accessible to nitrogen gas, viscous

490 hydrophobic oil may not penetrate them due to the restricted capillary penetration and

491 hydrophilicity of the inner pore surface. Therefore, breaking these pores in the pre-treatment and

492 PMMA grafting steps could benefit access to the oil.

493 
(a)

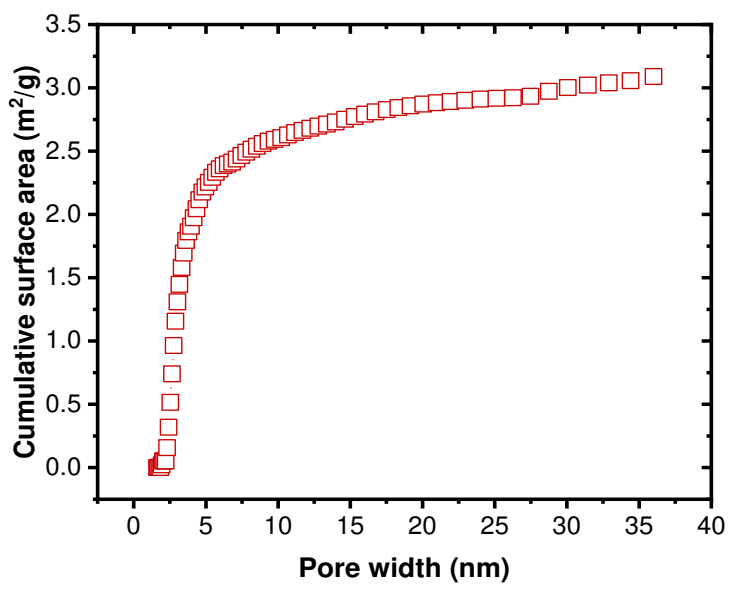

(b)

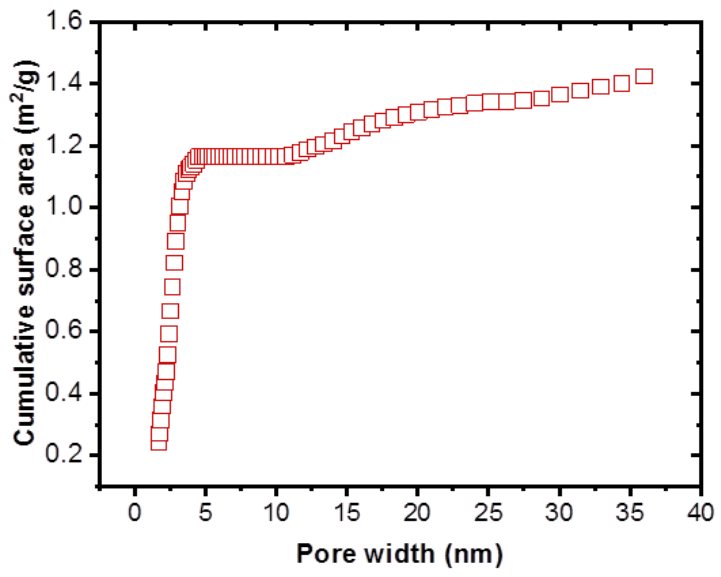

(c)

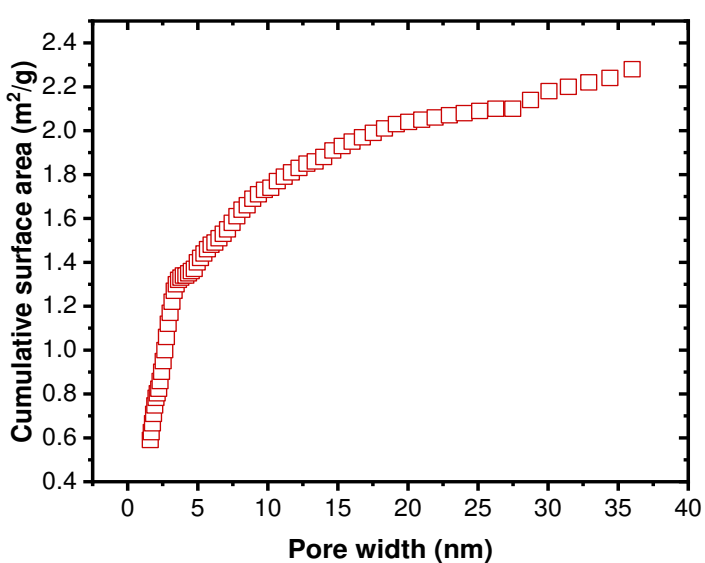

(d)

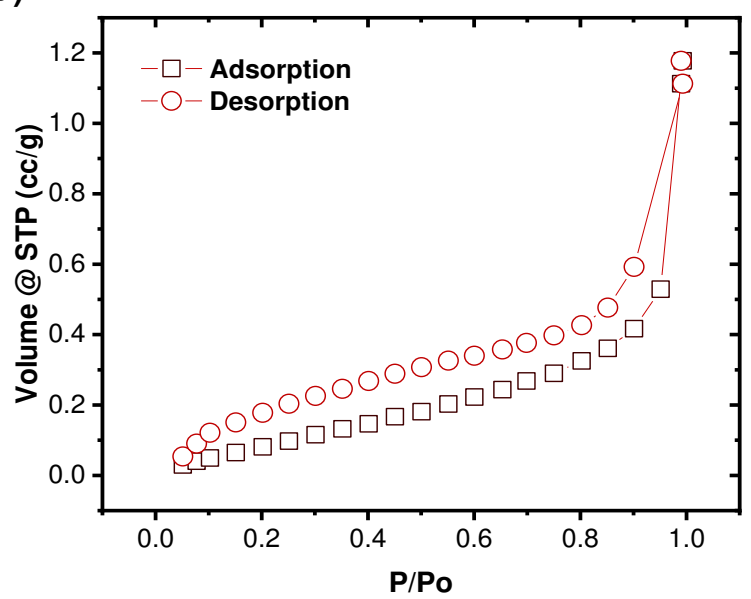

(e)

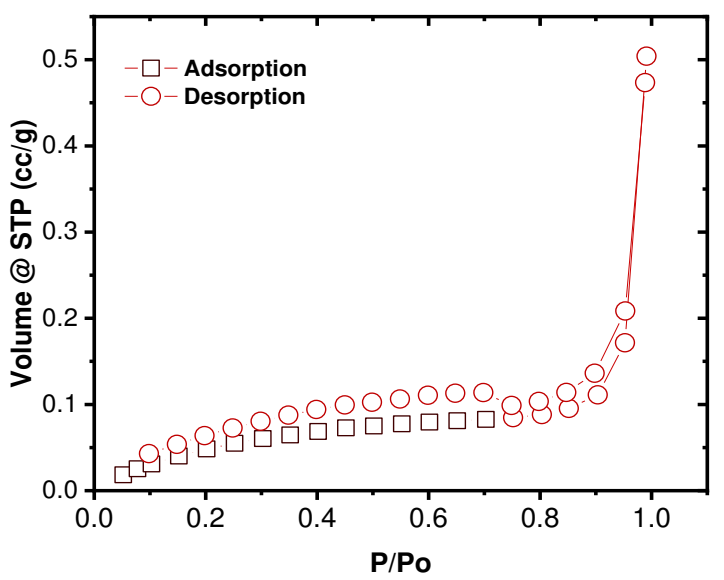

(f)

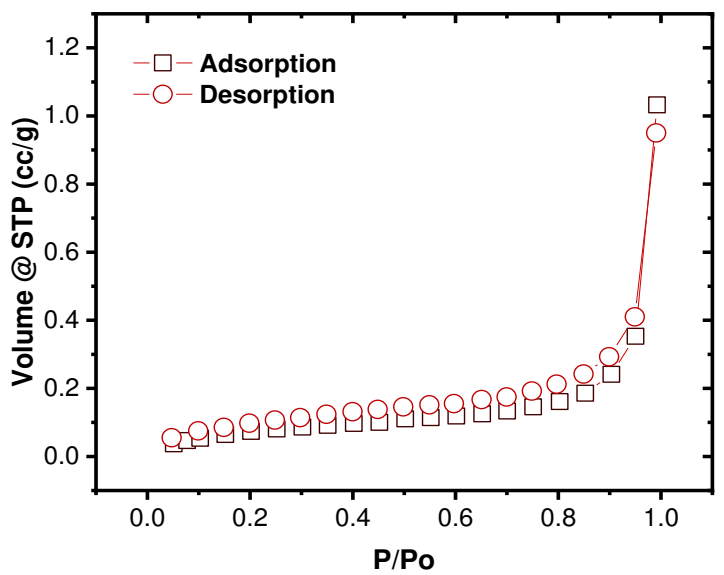

494

495

496

497

498 
499 Table 1 BET surface area and pore width of pristine, pretreated and WS-g-PMMA

\begin{tabular}{llll}
\hline Sample & $\begin{array}{l}\text { BET surface area } \\
\left(\mathrm{m}^{2} / \mathrm{g}\right)\end{array}$ & $\begin{array}{l}\text { Pore size } \\
(\mathrm{nm})\end{array}$ & $\begin{array}{l}\text { Pore volume } \\
(\mathrm{cc} / \mathrm{g})\end{array}$ \\
\hline Pristine & 3.84 & $1.6-6.5,7-20,26-32$ & $1.6 \times 10^{-2}$ \\
Pre-treated & 2.60 & $1.6-5,10-24,26-34$ & $8.0 \times 10^{-3}$ \\
WS-g-PMMA & 2.99 & $1.6-4,4-12,28-32$ & $1.6 \times 10^{-2}$ \\
\hline
\end{tabular}

500

501

\section{3.3.4. Surface wettability of pristine, pretreated and WS-g-PMMA}

503 It is well-known that surface roughness and surface hydrophilicity/hydrophobicity are the main 504 two influential parameters determining surface wettability (Wenzel 1949; Chau et al. 2009). 505 Moreover, surface wettability is a crucial parameter for understanding the level of affinity of the 506 adsorbent to oil or water. Therefore, the surface wettability of pristine WS, pretreated WS, and 507 WS-g-PMMA was evaluated by measuring the water and oil contact angles (Figure 6). Water and 508 oil contact angles for pristine WS were found to be $0^{\circ}$ and $79^{\circ}$, respectively. Hydrogen bonding 509 between water molecules and abundant surface hydroxyl functional groups caused full penetration 510 of water droplets into the Surface of pristine WS (Xu et al. 2018). On the other hand, the 511 hydrophilic surface hydroxyl groups inhibited the adhesion of oil droplets on the Surface of 512 pristine WS. The broken surface porous structures might have resulted in the absorption of both 513 water and oil droplets by the pretreated WS, although the surface was hydrophilic, which is 514 consistent with similar observations reported previously (Xu et al. 2018). In contrast to the pristine 515 and pretreated WS, the water contact angle of WS-g-PMMA was very high $\left(111^{\circ}\right)$. On the other 516 hand, the oil contact angle for WS-g-PMMA was $0^{\circ}$. The very high-water contact angle and zero 517 oil contact angle confirm the high hydrophobicity and oleophilicity of WS-g-PMMA. Therefore, 518 the WS-g-PMMA prepared in this study could be a promising candidate for the adsorptive removal 519 of hydrocarbons from oily wastewater. 

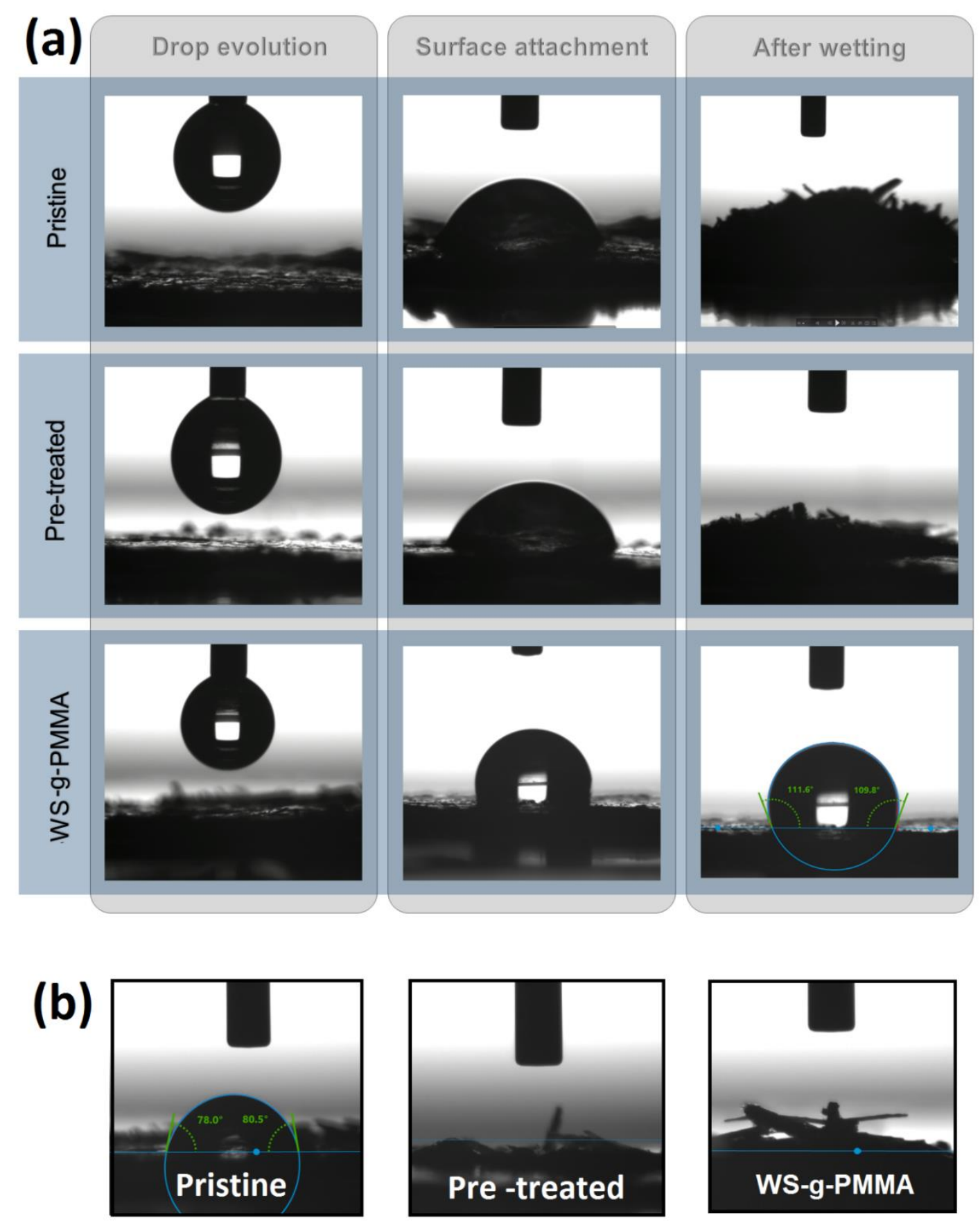

Figure 6. (a) Water contact angles of pristine WS, pretreated WS, and WS-g-PMMA in three different time-steps and (b) oil contact angles of all three adsorbents.

\section{3.4. Adsorption of oil from an oil-in-water emulsion}

\section{3.4.1. Effect of adsorbent contact time on oil adsorptivity}

526 A set of experiments were conducted to understand the influence of adsorbent contact time on oil 527 adsorption efficiency. The experiments were conducted at a constant shaking speed of 160 
528 oscillations $/ \mathrm{min}$, an initial oil concentration of $300 \mathrm{ppm}$, and an adsorbent dosage of $5 \mathrm{mg}$ at room 529 temperature. The time interval was set to five minutes, and the adsorption experiments were 530 conducted until the final oil concentration in the bulk liquid reached a constant value. A significant 531 amount of oil was adsorbed initially due to the availability of many adsorption sites and eventually 532 reached equilibrium, as presented in Figure 7. In the case of pristine WS, the equilibrium was 533 reached earlier due to the low accessibility of oil to the hydrophilic tubular pores of WS and low 534 hydrophobic interactions between the surface of the straw and oil droplets. The overall duration of 535 the adsorption process for pretreated WS was reasonably higher than the pristine WS due to 536 increased exposure of the porous structure caused by the alkaline hydrogen peroxide pretreatment, 537 even though the surface of this pretreated WS is more hydrophilic than that of pristine WS. 538 Hydrophobic interactions between the WS-g-PMMA surface and the oil molecules, along with 539 smaller sizes of WS-g-PMMA particles, the formation of a percolating network, exposed vessels, 540 and vessel to vessel pitting contributed to high oil adsorption. It increased the oil rejection, oil 541 adsorption capacity, and the overall duration of the adsorption process. The oil removal efficiency 542 of WS-g-PMMA was about 4 times higher than pristine WS and 1.6 times higher than pretreated 543 WS. The oil adsorption capacity increased from $300 \mathrm{mg} / \mathrm{g}$ to $700 \mathrm{mg} / \mathrm{g}$ upon pre-treatment and 544 from $700 \mathrm{mg} / \mathrm{g}$ to $1075 \mathrm{mg} / \mathrm{g}$ upon grafting of PMMA. In a similar work by (Mysore et al. 2005), 545 vermiculite hydrophobized by mixing with carnauba wax was analyzed for separating oil and 546 water. The batch study results indicated the adsorption capacity to be $108.4 \mathrm{mg} / \mathrm{g}, 78.14 \mathrm{mg} / \mathrm{g}$, $54786.54 \mathrm{mg} / \mathrm{g}$, and $3.97 \mathrm{mg} / \mathrm{g}$ for standard mineral oil, vegetable oil, kutwell oil, and refinery effluent, 548 respectively. In another work (Ibrahim et al. 2009), barley straw was chemically modified using $549 \mathrm{NaOH}$ and cationic surfactant hexadecylpyridinium chloride monohydrate. The maximum 550 adsorption capacities were found to be $613.3 \mathrm{mg} / \mathrm{g}$ and $584.2 \mathrm{mg} / \mathrm{g}$ for canola oil and standard 551 mineral oil, respectively. WS-g-PMMA has demonstrated an explicitly high adsorption capacity 552 of $1075 \mathrm{mg} / \mathrm{g}$ respectively, even in the case of low-density diesel oil. 

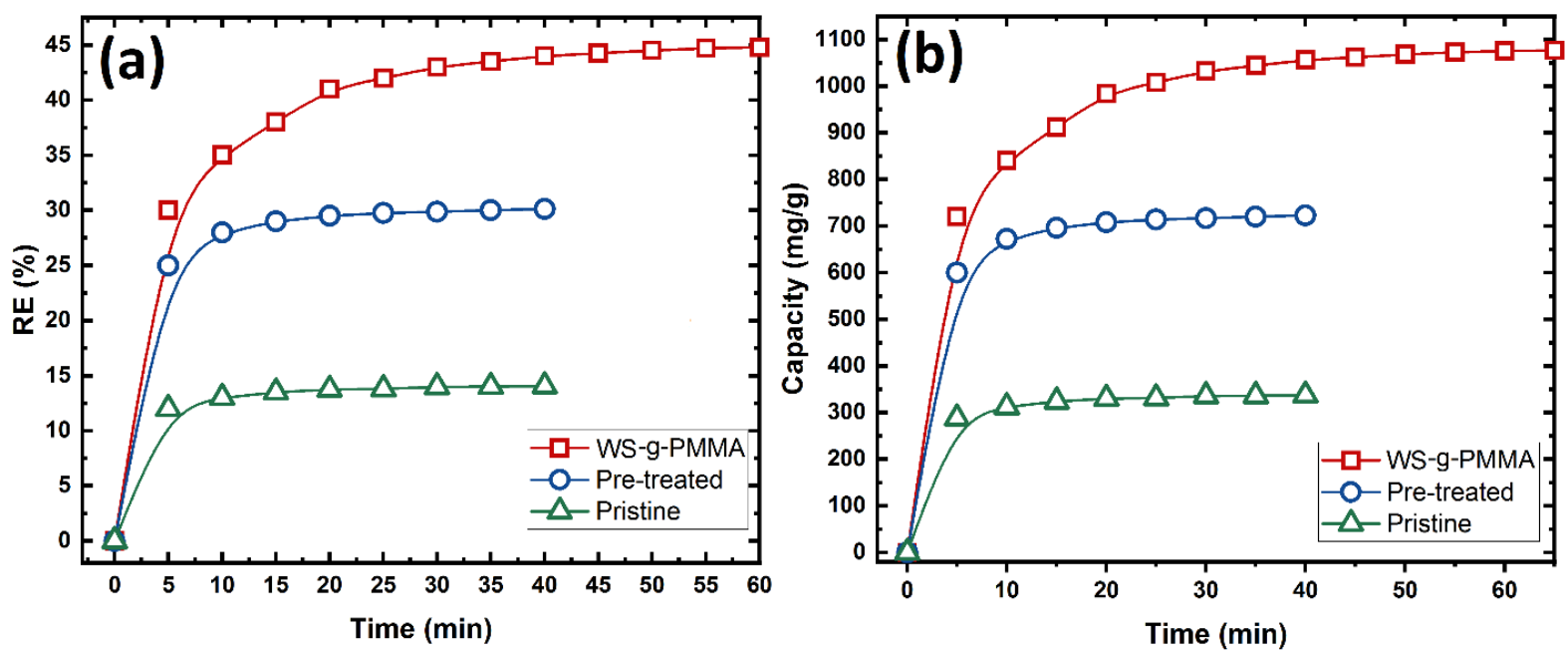

554

555

556

557

\section{8}

559

560

561

562

563

565

566 564 concentration. The reason behind higher removal efficiencies at the higher adsorbent dosage and

Figure 7. Effect of contact time on (a) oil removal efficiency and (b) oil adsorption capacity of pristine, pretreated, and WS-g-PMMA for 300ppm initial oil concentration, 5mg adsorbent dosage, and 160oscillations/min shaking speed.

\subsubsection{Effect of initial oil concentration and adsorbent dosage}

The effect of different adsorbent dosages and the oil concentration was studied by varying the amount of WS-g-PMMA from $5 \mathrm{mg}$ to $25 \mathrm{mg}$ for initial oil concentrations of 100, 200, and 300 ppm. The contact time and shaking speed were kept constant at 30 minutes and 160 oscillations/min, respectively. As shown in Figure 8a, the adsorptive oil removal efficiency (RE)

63 increased linearly with an increase in adsorbent dosage, and it was higher for 100 ppm oil 65 lower oil concentrations is the availability of higher adsorption sites for oil accumulation sufficient to accommodate all the oil present in the bulk solution. 

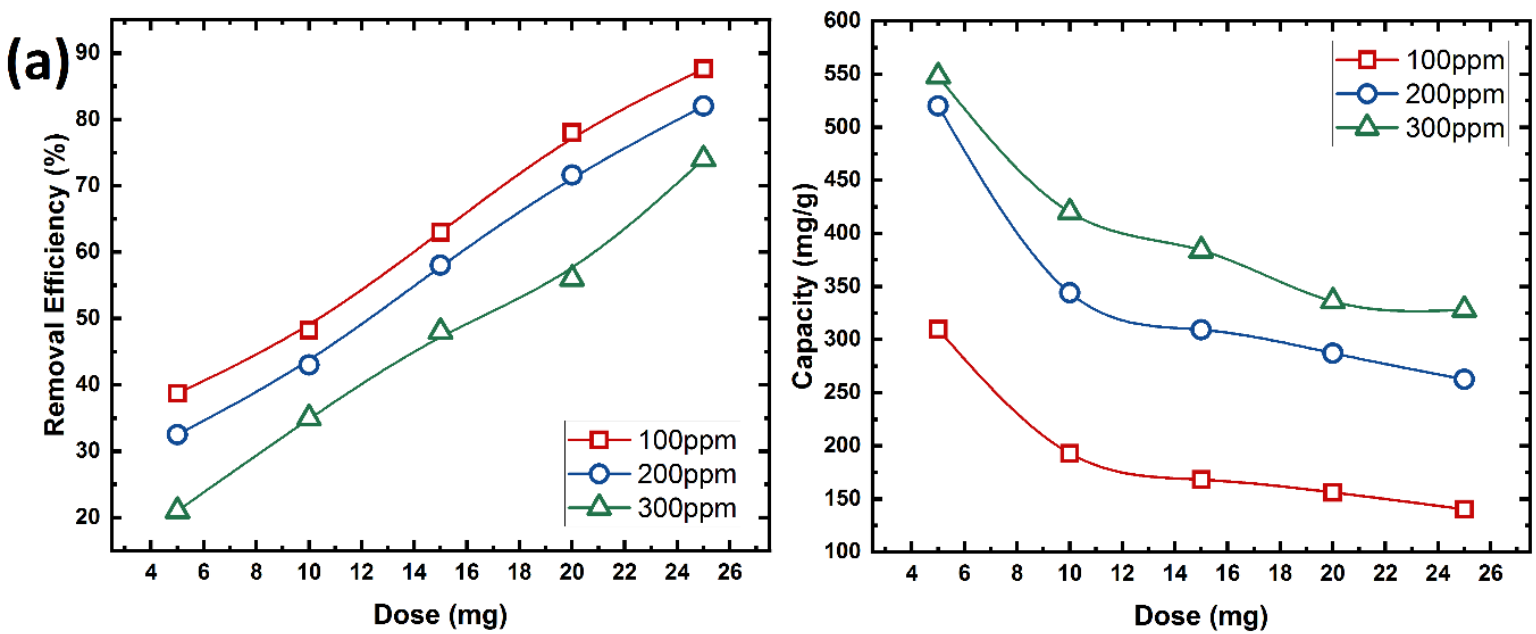

(b)
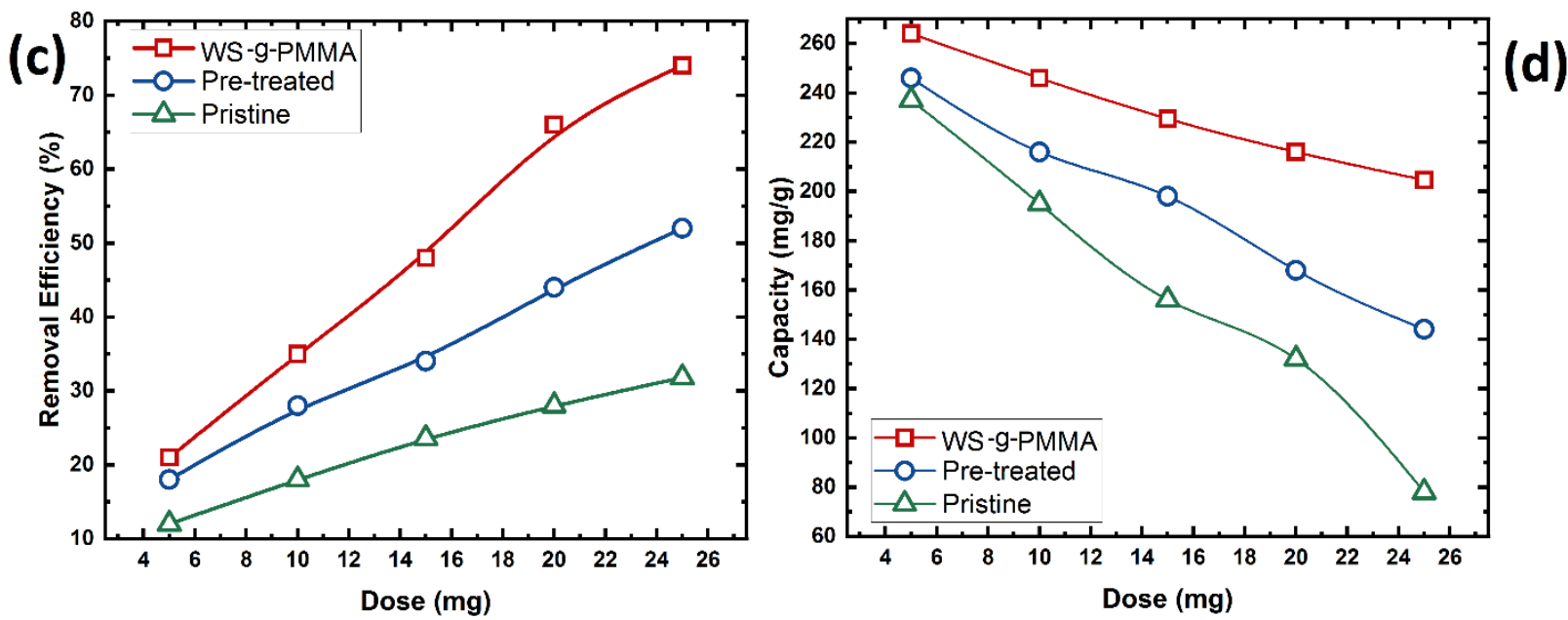

568

569

570

571

572

573

574

575

576

577

578

579

580

581

582

Figure 8. Effect of initial oil concentration and adsorbent dosage on (a) the oil removal efficiency and (b) oil adsorption capacity of WS-g-PMMA. Effect of adsorbent dosage on (c) oil removal efficiency and (d) oil adsorption capacity of pristine, pretreated, and WS-g-PMMA.

In contrast to the increase in oil removal efficiency, the adsorption capacity of WS-g-PMMA decreased with the increase in adsorbent dosage and with the decrease in oil concentration (Figure 8b). The hike in the ratio of adsorption sites to the amount of oil in the bulk liquid declined the total adsorption capacity. The adsorption capacity $\mathrm{q}_{\mathrm{t}}$ is measured by dividing the mass of oil adsorbed by the total mass of the adsorbent. Hence, the increase in the amount of adsorbed oil remains lower than the increase in the amount of adsorbent, leading to a decreasing trend in the adsorption capacity. The effect of adsorbent dosage on the removal efficiency and adsorption capacity was compared for pristine, pretreated, and WS-g-PMMA by varying the adsorbent dosage from $5 \mathrm{mg}$ to $15 \mathrm{mg}$ while keeping the oil concentration constant at $300 \mathrm{ppm}$. The order of oil removal efficiency for the increase in adsorbent dosage was WS-g-PMMA > pretreated WS > 
583 pristine WS (Figure $8 \mathbf{c}$ and $\mathbf{d}$ ). This indicates that surface modification enabled easy penetration 584 of oil by exposing the pores, as evident from the SEM micrographs. More importantly, it 585 significantly increased the hydrophobicity of the surface, as indicated by the FTIR and contact 586 angle results.

\section{3.4.3. Adsorption isotherm models}

589 After evaluating the influence of adsorbent dosage and oil concentration on oil removal efficiency 590 and adsorption capacity, Langmuir and Freundlich adsorption isotherms were used to understand 591 the oil adsorption mechanism. Figures 9 a and b show the linearized plots for Langmuir and 592 Freundlich isotherms, respectively. The Freundlich isotherm provided a better fit to the 593 experimental $C_{\mathrm{e}}$ and $q_{\mathrm{e}}$ values. This strongly indicates the heterogeneity of adsorption sites as well 594 as the involvement of multilayer adsorption of oil. Therefore, adsorption efficiency will be higher 595 at the initial stages of adsorption since it is based on the direct interaction of adsorption sites with 596 oil. The adsorption efficiency will be reduced exponentially with time since adsorption at these 597 stages predominantly involves the interaction of the adsorbed oil layer with excess oil in the bulk 598 solution. These results are in line with work on adsorption of palm oil mill effluent using sago bark 599 (Wahi et al. 2017), where the experimental values fitted well with Freundlich isotherm, indicating 600 heterogeneous adsorption of oil on the bark material. Diesel oil consisting of linear hydrocarbons 601 of different chain lengths contributed to the multilayer heterogeneous adsorption over the 602 mesoporous structure of WS-g-PMMA (Diraki et al. 2018). The Freundlich parameters $n$ and $K_{\mathrm{f}}$ 603 values being greater than 1, as shown in Figure 9b, strongly suggest a higher adsorption capacity 604 of WS-g-PMMA for diesel oil. 

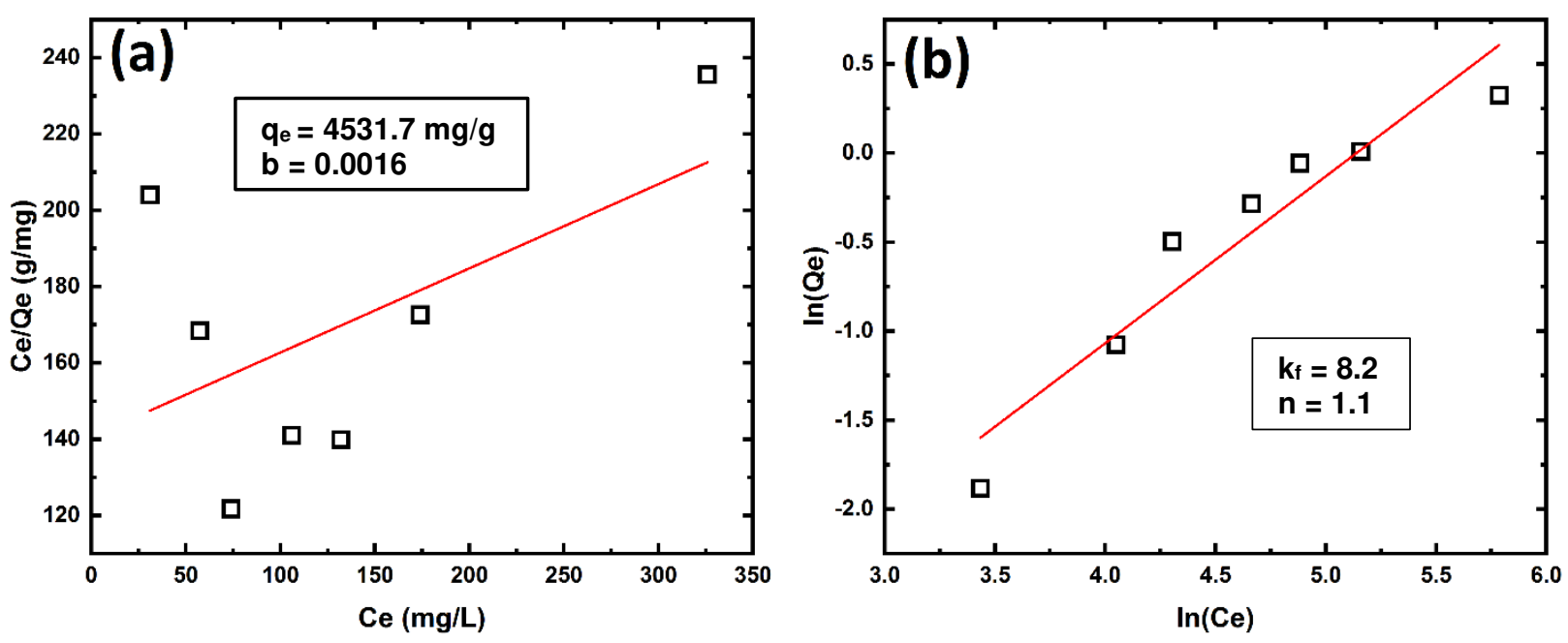

606

607

608

609

610

611

612

613

614

615

616

617

618

619

620

621

622

623

624

625

626

627

Figure 9. (a) Langmuir and (b) Freundlich linear fitting for adsorption of emulsified oil on WS-g-PMMA.

\subsubsection{Adsorption kinetics}

Large-scale application of any adsorption-based filtration system demands evaluating the adsorption rate and the corresponding adsorption equilibrium time. Pseudo-first order and pseudosecond-order kinetics models are widely applied to determine the adsorption kinetics. As seen in

Figure 10 b, the pseudo-second-order equation provided a better fit with the experimental oil adsorption data for all three WS samples featuring an $R^{2}$ value as high as 0.999. At equilibrium, the oil adsorption capacity $\left(q_{e}=1129 \mathrm{mg} / \mathrm{g}\right.$, Table 3.) is very close to the experimental values $(1075 \mathrm{mg} / \mathrm{g})$. The predicted values of $q_{e}$ from the pseudo-first-order equation, on the other hand, were not even close to the experimental data, even though the $R^{2}$ values are reasonably acceptable. Based on these observations, it can be concluded that the adsorption process follows a pseudosecond-order rate for all three WS samples. The pseudo-second-order rate implies that the rate of adsorption decreased with time. In a similar work (Lin and Chen 2015) on polyethyleneimine modified rice husk, the pseudo-second-order kinetic equation provided the best fit with $\mathrm{R}^{2}>0.998$. In addition, the adsorption capacity of the material for treating soybean oil-based emulsion was found to be $428.1 \mathrm{mg} / \mathrm{g}$ and $469.5 \mathrm{mg} / \mathrm{g}$ at $20^{\circ} \mathrm{C}$ and $40{ }^{\circ} \mathrm{C}$, respectively. The pseudo-second-order rate implies that the rate of adsorption decreased with time. This is also consistent with the better fitting of the adsorption data with Freundlich adsorption isotherm, which generally demonstrates higher initial adsorption due to direct interaction of adsorbent with adsorbate followed by slower adsorption with time due to secondary interaction of the surface adsorbed adsorbate with the 
628 adsorbate in the bulk liquid. The higher hydrophobic interaction between the PMMA grafted on 629 WS and oil molecules contributed to stronger physisorption and significantly improved the oil uptake rate by the WS-g-PMMA sample.

631

632

633

634

635

636

637

638

639

640

641

642

643

644

645 (a)

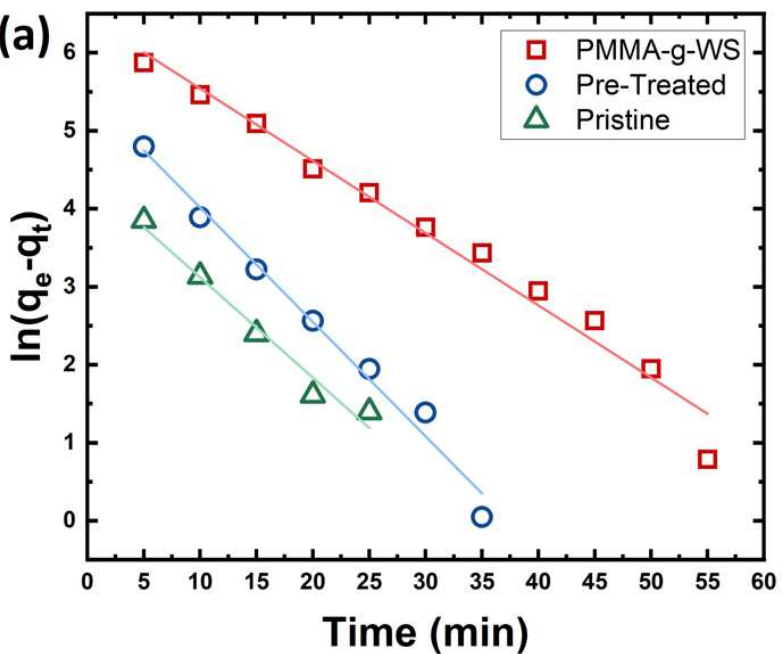

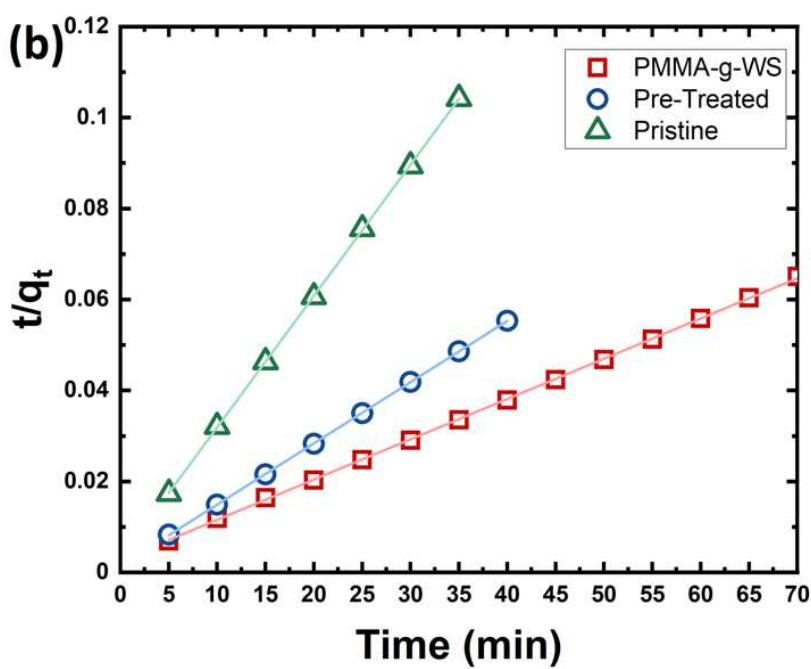

Figure 10. (a) Pseudo-first order and (b) pseudo-second-order kinetic models for removing emulsified oil using pristine, pretreated, and WS-g-PMMA at ambient temperature and shaking speed of 160 oscillations/min.

Table 3. Pseudo-first-order and pseudo-second-order kinetic model parameters for the removal of emulsified oil using pristine and pretreated WS as well as WS-g-PMMA.

\begin{tabular}{lccccccc}
\hline \multirow{2}{*}{ Sample } & \multicolumn{2}{c}{ Pseudo-first order kinetic parameters } & & \multicolumn{3}{c}{ Pseudo-second order kinetic parameters } \\
\cline { 2 - 3 } & $q_{e}$ & $k_{l}(\mathrm{~g} / \mathrm{mg} . \mathrm{h})$ & $R^{2}$ & & $k_{2}(\mathrm{~g} / \mathrm{mg} . \mathrm{h})$ & $q_{e}(\mathrm{mg} / \mathrm{g})$ & $R^{2}$ \\
\hline WS-g-PMMA & 645 & 0.0927 & 0.921 & & 0.0003 & 1129 & 0.999 \\
Pre-treated WS & 241 & 0.1467 & 0.924 & & 0.0013 & 741 & 0.999 \\
Pristine WS & 82 & 0.1287 & 0.990 & & 0.0028 & 346 & 0.999 \\
\hline
\end{tabular}

\subsubsection{Comparison of oil absorptivity with literature reported adsorbents}

There are several reports on different types of straw-based adsorbents featuring exceptionally high oil adsorption capacity in the range of 17.5-28.8 g/g (Table 4). However, most of these adsorbents have several concerns, such as stability of bonds (e.g., ester and silyloxy) formed between the surface of straw and hydrophobization agents, a large excess of chemical usage including many toxic ones, multistep processing, and/or usage of fluorocarbons as hydrophobization agents. Apart from these concerns, the oil adsorption capacity for these adsorbents is not comparable with the current study since the oil adsorption measurement process for these high adsorption studies was 
646 not for diluted emulsified oil. In many cases, an overestimation of the adsorption capacity is 647 possible. Many of the studies even did not provide the adsorption capacity for raw straw. In some 648 studies, raw straw showed significantly higher adsorption capacity (5 to $8.2 \mathrm{~g} / \mathrm{g}$ ) than obtained in 649 this study $(346 \mathrm{mg} / \mathrm{g})$. Even raw barley straw was reported to have extensively higher oil 650 adsorptivity (6.5-12 g/g) (Husseien et al. 2009) than surfactant modified barley straw (613.3 mg/g 651 Table 4). However, when compared to the studies on the systematic kinetic studies for oil 652 adsorption using dilute emulsified oil, the adsorption capacity of WS-g-PMMA is significantly 653 higher than PEI modified rice husk and surfactant modified barley straw. The adsorption capacity 654 of WS-g-PMMA is also higher than activated carbon and graphene nanoplatelets while slightly 655 lower than thermally reduced graphene and graphene oxide. However, carbon-based materials are 656 characterized by high costs and a high carbon footprint.

658 Table 4. Comparison of oil absorptivity with other modified straw reported in the literature

\begin{tabular}{|c|c|c|c|c|c|}
\hline Adsorbent & Modification & Oil type & $\begin{array}{l}\text { Sorption } \\
\text { capacity }\end{array}$ & Remarks & Reference \\
\hline Rice straw & Acetylation & $\begin{array}{l}\text { Suspended } \\
\text { machine oil } \\
20 \mathrm{~g} \text { in an } \\
\text { unknown } \\
\text { amount of } \\
\text { water and } 0.5 \\
\text { straw }\end{array}$ & $24.0 \mathrm{~g} / \mathrm{g}$ & $\begin{array}{l}\text { 1) Not emulsified oil } \\
\text { 2) Ester bonds } \\
\text { 3) Large excess chemical usage } \\
\text { 4) No raw straw adsorption data }\end{array}$ & $\begin{array}{l}\text { (Sun et al. } \\
2002)\end{array}$ \\
\hline Wheat straw & Acetylation & Same as above & $28.8 \mathrm{~g} / \mathrm{g}$ & $\begin{array}{l}\text { Same as above } \\
\text { (Sun et al. 2002) }\end{array}$ & $\begin{array}{l}\text { (Sun et al. } \\
2004 \text { ) }\end{array}$ \\
\hline Wheat straw & $\begin{array}{l}\text { 1) Pre-treatment with } \\
\text { Toluene-ethanol } \\
\text { refluxing to remove was } \\
\text { and resins } \\
\text { 2) Pre-treatment with } \\
\mathrm{NaClO}_{2} \text { to remove lignin } \\
\text { 3) } \mathrm{Pre}_{\text {treatment } \mathrm{NaOH}} \\
\text { to remove cellulose and } \\
\text { hemicellulose } \\
\text { 4) Acetylation }\end{array}$ & $\begin{array}{l}\text { Pure oils } \\
\text { 1) Diesel } \\
\text { 2) Corn } \\
\text { Oil Slick } \\
\text { 1) Diesel } \\
\text { 2) Corn oil }\end{array}$ & $\begin{array}{l}\text { Pure oil } \\
\text { 1) } 24.2 \mathrm{~g} / \mathrm{g} \\
\text { 2) } 25.5 \mathrm{~g} / \mathrm{g} \\
\text { Oil Slick } \\
\text { 1) } 22.4 \mathrm{~g} / \mathrm{g} \\
\text { 2) } 24.7 \mathrm{~g} / \mathrm{g}\end{array}$ & $\begin{array}{l}\text { 1) and 2) same as above (Sun et al. } \\
\text { 2004) } \\
\text { 3) Extreme use of chemicals } \\
\text { (including toxic toluene, } \mathrm{NaClO}_{2} \text {, } \\
\text { DMAc, NBS) in multiple Pre- } \\
\text { treatment and acetylation steps } \\
\text { 4) Raw straw adsorptivity: diesel oil } \\
\text { and diesel oi slick } 8.2 \text { and } 7.8 \mathrm{~g} / \mathrm{g} \text {, } \\
\text { respectively }\end{array}$ & $\begin{array}{l}\text { (Lv et al. } \\
2017)\end{array}$ \\
\hline Wheat straw & $\begin{array}{l}\text { 1) } 3 \text { steps chemical pre- } \\
\text { treatment as above } \\
\text { 2) Esterification with } \\
\text { Palmitic Acid }\end{array}$ & $\begin{array}{l}\text { Pure oil } \\
\text { 1) Diesel } \\
\text { 2) Peanut } \\
\text { 3) Lubricant } \\
\text { Oil slick } \\
\text { 1) Diesel } \\
\text { 2) Peanut } \\
\text { 3) Lubricant }\end{array}$ & $\begin{array}{l}\text { Pure oil } \\
\text { 1) } 24.3 \mathrm{~g} / \mathrm{g} \\
\text { 2) } 24.9 \mathrm{~g} / \mathrm{g} \\
\text { 3) } 22.7 \mathrm{~g} / \mathrm{g} \\
\text { Oil slick } \\
\text { 1) } 23.5 \mathrm{~g} / \mathrm{g} \\
\text { 2) } 23.7 \mathrm{~g} / \mathrm{g} \\
\text { 3) } 21.9 \mathrm{~g} / \mathrm{g}\end{array}$ & $\begin{array}{l}\text { 1), 2), and 3) are like above (Lv et } \\
\text { al. 2017) } \\
\text { 4) Raw straw adsorptivity: diesel oil } \\
\text { and diesel oi slick } 7.1 \text { and } 6.2 \mathrm{~g} / \mathrm{g} \text {, } \\
\text { respectively }\end{array}$ & $\begin{array}{l}\text { (Tang et } \\
\text { al. 2018) }\end{array}$ \\
\hline
\end{tabular}




\begin{tabular}{|c|c|c|c|c|c|}
\hline Cron straw & $\begin{array}{l}\text { 1) Alkaline } \mathrm{H}_{2} \mathrm{O}_{2} \text { Pre- } \\
\text { treatment } \\
\text { 2) Synthesis of } \mathrm{ZnO} \\
\text { particles } \\
\text { 3) } \mathrm{ZnO} \text { deposition and } \\
\text { HDTMOS } \\
\text { functionalization }\end{array}$ & $\begin{array}{l}\text { Pure oil } \\
\text { 1 Diesel oil } \\
\text { 2) Crude oil } \\
\text { 3) Bean oil }\end{array}$ & $\begin{array}{l}\text { 1) } 18 \mathrm{~g} / \mathrm{g} \\
\text { 2) } 20.4 \mathrm{~g} / \mathrm{g} \\
\text { 3) } 22 \mathrm{~g} / \mathrm{g}\end{array}$ & $\begin{array}{l}\text { 1) Adsorption is not for emulsified } \\
\text { oil } \\
\text { 2) Silyloxy bond with the straw } \\
\text { may not be stable for long-term } \\
\text { operation. } \\
\text { 3) Large amount of chemical } \\
\text { usage. } \\
\text { 4) Raw straw adsorptivity pure } \\
\text { diesel oil ca. } 5 \mathrm{~g} / \mathrm{g}\end{array}$ & $\begin{array}{l}\text { (Zang et } \\
\text { al. 2016) }\end{array}$ \\
\hline Corn straw & $\begin{array}{l}\text { 1) Alkaline } \mathrm{H}_{2} \mathrm{O}_{2} \text { Pre- } \\
\text { treatment } \\
\text { 2) Synthesis of } \mathrm{SiO}_{2} \\
\text { particles } \\
3 \mathrm{SiO}_{2} \text { deposition and } \\
\text { PTES functionalization }\end{array}$ & $\begin{array}{l}\text { Pure oil } \\
\text { 1 Diesel oil } \\
\text { 2) Crude oil } \\
\text { 3) Bean oil }\end{array}$ & $\begin{array}{l}\text { 1) } 17.5 \mathrm{~g} / \mathrm{g} \\
\text { 2) } 20.3 \mathrm{~g} / \mathrm{g} \\
\text { 3) } 22.6 \mathrm{~g} / \mathrm{g}\end{array}$ & $\begin{array}{l}\text { 1), 2), 4) same as above (Zang et } \\
\text { al. 2016) } \\
\text { 3) Large amount of chemical use: } \\
\text { PTES is used to reduce chemical, } \\
\text { but fluorocarbon is discouraged }\end{array}$ & $\begin{array}{l}\text { (Xu et al. } \\
2018)\end{array}$ \\
\hline Corn straw & $\begin{array}{l}\text { 1) Alkaline } \mathrm{H}_{2} \mathrm{O}_{2} \text { Pre- } \\
\text { treatment } \\
\text { 2) } \mathrm{SiO}_{2} \text { particles growth } \\
\text { on } \mathrm{WS} \\
\text { 3) Synthesis of } \mathrm{ZnO} \\
\text { particles } \\
\text { 4) } \mathrm{ZnO} \text { deposition and } \\
\text { OTES functionalization }\end{array}$ & $\begin{array}{l}\text { Pure oil } \\
\text { 1) Diesel oil } \\
\text { 2) Crude oil } \\
\text { 3) Bean oil }\end{array}$ & $\begin{array}{l}\text { 1) } 18.70 \mathrm{~g} / \mathrm{g} \\
\text { 2) } 20.05 \mathrm{~g} / \mathrm{g} \\
\text { 3) } 22.50 \mathrm{~g} / \mathrm{g}\end{array}$ & $\begin{array}{l}\text { 1), 2), and 3) same as for (Zang et } \\
\text { al. 2016) } \\
\text { 4) Extreme chemical usage } \\
\text { 5) Many steps } \\
\text { 6) All the raw materials are } \\
\text { fluorine-free }\end{array}$ & $\begin{array}{l}\text { (Tan et al. } \\
2021 \text { ) }\end{array}$ \\
\hline Rice husk & Polyethyleneimine & $\begin{array}{l}450 \quad \mathrm{ppm} \\
\text { Emulsified } \\
\text { soybean oil }\end{array}$ & $428 \mathrm{mg} / \mathrm{g}$ & $\begin{array}{l}\text { 1) Emulsified oil } \\
\text { 2) The chemistry of PEI } \\
\text { modification is not clear } \\
\text { 3) Lower adsorptivity } \\
\text { 4) Raw rice husk adsorptivity ca. } \\
100 \mathrm{mg} / \mathrm{g}\end{array}$ & $\begin{array}{l}\text { (Lin and } \\
\text { Chen } \\
\text { 2015) }\end{array}$ \\
\hline Barley straw & $\begin{array}{l}\text { 1) Pre-treatment with } \\
\mathrm{NaOH} \\
\text { 2) Cationic surfactant } \\
\mathrm{CPC} \text { adsorption }\end{array}$ & $\begin{array}{l}\text { Emulsified:1) } \\
\text { Canola } \\
\text { 2) Mineral }\end{array}$ & $\begin{array}{l}\text { 1) } 613.3 \\
\mathrm{mg} / \mathrm{g} \\
\text { 2) } 584.2 \\
\mathrm{mg} / \mathrm{g}\end{array}$ & $\begin{array}{l}\text { 1) Emulsified oil } \\
\text { 2) Physiosorbed surfactant can } \\
\text { leach } \\
\text { 3) Lower adsorptivity }\end{array}$ & $\begin{array}{l}\text { (Ibrahim } \\
\text { et al. } \\
\text { 2009) }\end{array}$ \\
\hline Wheat straw & $\begin{array}{l}\text { 1) Alkaline } \mathrm{H}_{2} \mathrm{O}_{2} \text { Pre- } \\
\text { treatment } \\
\text { 2) PMMA grafting }\end{array}$ & $\begin{array}{l}300 \quad \mathrm{ppm} \\
\text { emulsified } \\
\text { diesel oil }\end{array}$ & $1129 \mathrm{mg} / \mathrm{g}$ & $\begin{array}{l}\text { 1) Emulsified oil } \\
\text { 2) One-step eco-friendly pre- } \\
\text { treatment } \\
\text { 3) Less chemical usage } \\
\text { 4) Water as the solvent } \\
\text { 5) PMMA ecofriendly } \\
\text { 6) PMMA stable } \\
\text { 7) Higher adsorptivity }\end{array}$ & $\begin{array}{l}\text { This } \\
\text { study }\end{array}$ \\
\hline $\begin{array}{l}\text { Activated } \\
\text { carbon }\end{array}$ & - & $\begin{array}{l}165 \quad \mathrm{ppm} \\
\text { oilfield } \\
\text { produced } \\
\text { water }\end{array}$ & $334 \mathrm{mg} / \mathrm{g}$ & $\begin{array}{l}\text { 1) Emulsified oil } \\
\text { 2) High carbon footprint } \\
\text { 3) Expensive } \\
\text { 4) Lower adsorptivity }\end{array}$ & $\begin{array}{l}\text { (Okiel et } \\
\text { al. 2011) }\end{array}$ \\
\hline $\begin{array}{l}\text { Thermally } \\
\text { reduced } \\
\text { graphene }\end{array}$ & - & $\begin{array}{l}200 \quad \mathrm{ppm} \\
\text { Diesel-water } \\
\text { emulsion }\end{array}$ & $1550 \mathrm{mg} / \mathrm{g}$ & $\begin{array}{l}\text { 1) Emulsified oil } \\
\text { 2) High carbon footprint } \\
\text { 3) Expensive }\end{array}$ & $\begin{array}{l}\text { (Diraki et } \\
\text { al. 2018) }\end{array}$ \\
\hline
\end{tabular}




\begin{tabular}{|l|l|l|l|l|l|}
\hline $\begin{array}{l}\text { Graphene } \\
\text { nanoplatelets }\end{array}$ & - & $\begin{array}{l}200 \quad \mathrm{ppm} \\
\text { Diesel-water } \\
\text { emulsion }\end{array}$ & $805 \mathrm{mg} / \mathrm{g}$ & $\begin{array}{l}\text { 1) Emulsified oil } \\
\text { 2) High carbon footprint } \\
\text { 3) Expensive }\end{array}$ & $\begin{array}{l}\text { (Diraki et } \\
\text { al. 2018) }\end{array}$ \\
\hline $\begin{array}{l}\text { Graphene } \\
\text { oxide }\end{array}$ & - & $\begin{array}{l}200 \quad \mathrm{ppm} \\
\text { Diesel-water } \\
\text { emulsion }\end{array}$ & $1335 \mathrm{mg} / \mathrm{g}$ & $\begin{array}{l}\text { 1) Emulsified oil } \\
\text { 2) High carbon footprint }\end{array}$ & $\begin{array}{l}\text { 3) Expensive } \\
\text { al. 2019) }\end{array}$ \\
\hline
\end{tabular}

\section{Conclusion}

661 In this study, a simple radical polymerization was explored to enhance the oil absorptivity of an 662 agricultural by-product, wheat straw (WS). An attempt has been made to utilize it as an economical 663 and eco-friendly adsorbent for separating oil from oil-in-water emulsions. The pristine WS was 664 pretreated with alkaline hydrogen peroxide, and PMMA was grafted subsequently in an aqueous 665 solvent using cerium ammonium nitrate as a redox radical initiator. The alkaline hydrogen 666 peroxide pre-treatment played a crucial role in exposing the mesopores, which are vital for any 667 adsorption process. The SEM micrographs indicated the presence of mesopores. In addition, the 668 PMMA grafting enhanced the surface hydrophobicity, leading to stronger hydrophobic 669 interactions between the oil droplets and the grafted surface moieties. The enhanced open surface 670 porous features and the hydrophobicity of WS-g-PMMA contributed to high oil adhesion as 671 observed by the $0^{\circ}$ oil contact angle, which in turn led to an increment in the oil adsorption by 3.3 672 times. The experimental adsorptivity data fit well with Freundlich isotherm, indicating the 673 heterogeneity of adsorption sites as well as multilayer adsorption of oil. The adsorption kinetics 674 was best represented by the pseudo-second-order kinetic model supporting the Freundlich isotherm 675 model of multilayer formation. The adsorption capacity of WS-g-PMMA was found to be 1129 $676 \mathrm{mg} / \mathrm{g}$, which is reasonably high and demonstrates its potential for economical treatment of oily 677 wastewater since the overall cost-efficiency of waste WS along with a simple chemical 678 modification for grafting PMMA process will allow the use of a large amount of this adsorbent for 679 large scale applications.

\section{Acknowledgment}

682 The authors wish to acknowledge the financial support from the Natural Sciences and Engineering 683 Research Council of Canada (NSERC). The authors would like to thank BioLargo water for 684 supporting this project and providing wheat straw samples. 
687 * Email: maislam@ualberta.ca, sadrzade@ualberta.ca

\section{Declaration of interest}

The authors declare no competing interests.

691

\section{References}

Abd-Talib N, Ahmad A, Mohd-Setapar S, et al (2018) Removal of silica from rice straw by using alkaline hydrogen peroxide solution in a fixed bed column. J Mater Environ Sci 9:864-872. https://doi.org/10.26872/jmes.2018.9.3.95

Adebajo MO, Frost RL, Kloprogge JT, et al (2003a) Porous Materials for Oil Spill Cleanup : A Review of Synthesis. J Porous Mater 10:159-170.

Adebajo MO, Frost RL, Kloprogge JT, et al (2003b) Porous materials for oil spill cleanup: a https://doi.org/10.1023/A:1027484117065 review of synthesis and absorbing properties. J Porous Mater 10:159-170

Al-Majed AA, Adebayo AR, Hossain ME (2012) A sustainable approach to controlling oil spills.

713 Brandt A, Gräsvik J, Hallett JP, Welton T (2013) Deconstruction of lignocellulosic biomass with J Environ Manage 113:213-227

Alaa El-Din G, Amer AA, Malsh G, Hussein M (2017) Study on the use of banana peels for oil spill removal. Alexandria Eng J. https://doi.org/10.1016/j.aej.2017.05.020

Alemdar N, Karagoz B, Erciyes AT, Bicak N (2007) Short communication A method for polymethymetacrylate coating via self-curable unsaturated polyester primer on metal and glass surfaces. 60:69-74. https://doi.org/10.1016/j.porgcoat.2007.06.005

Ali I, Arsh A, Mbianda XY, et al (2019) Graphene based adsorbents for remediation of noxious pollutants from wastewater. Environ Int 127:160-180. https://doi.org/10.1016/j.envint.2019.03.029

Beall GW (2003) The use of organo-clays in water treatment. Appl Clay Sci 24:11-20. https://doi.org/10.1016/j.clay.2003.07.006 ionic liquids. Green Chem 15:550-583. https://doi.org/10.1039/c2gc36364j

Chau TT, Bruckard WJ, Koh PTL, Nguyen A V (2009) A review of factors that affect contact angle and implications for flotation practice. Adv Colloid Interface Sci 150:106-115. 
https://doi.org/https://doi.org/10.1016/j.cis.2009.07.003

718 Chen J, Yi J, Sun P, et al (2009) Grafting from ramie fiber with poly (MMA) or poly (MA) via reversible addition-fragmentation chain transfer polymerization. Cellulose 16:1133-1145

Cheryan M, Rajagopalan N (1998) Membrane processing of oily streams. Wastewater treatment and waste reduction. J Memb Sci 151:13-28. https://doi.org/10.1016/S03767388(98)00190-2

723 Cychosz KA, Thommes M (2018) Progress in the Physisorption Characterization of Nanoporous

724 Gas Storage Materials. Engineering 4:559-566. https://doi.org/10.1016/j.eng.2018.06.001

725

726

Daud WMAW, Ali WSW, Sulaiman MZ (2003) Effect of activation temperature on pore development in activated carbon produced from palm cell. J Chem Technol Biotechnol 78:1-5. https://doi.org/10.1002/jctb.712

Deschamps G, Caruel H, Borredon M-E, et al (2003) Oil Removal from Water by Selective Sorption on Hydrophobic Cotton Fibers. 1. Study of Sorption Properties and Comparison with Other Cotton Fiber-Based Sorbents. Environ Sci Technol 37:1013-1015. https://doi.org/10.1021/es020061s

Ding S, Kantarelis E, Engvall K (2020) Effects of porous structure development and ash on the steam gasification reactivity of biochar residues from a commercial gasifier at different temperatures. Energies 13:. https://doi.org/10.3390/en13195004

Diraki A, Mackey H, McKay G, Abdala AA (2018) Removal of oil from oil-water emulsions using thermally reduced graphene and graphene nanoplatelets. Chem Eng Res Des 137:4759. https://doi.org/10.1016/j.cherd.2018.03.030

Diraki A, Mackey HR, McKay G, Abdala A (2019) Removal of emulsified and dissolved diesel oil from high salinity wastewater by adsorption onto graphene oxide. J Environ Chem Eng $7: 103106$

Dodson JR (2011) Wheat straw ash and its use as a silica source. Univ York 302

Fakhru'L-Razi A, Qudsieh IYM, Ahmad WMZWYMB, Rahman MZA (2001) Graft copolymerization of methyl methacrylate onto sago starch using ceric ammonium nitrate and potassium persulfate as redox initiator systems. J Appl Polym Sci 82:1375-1381. https://doi.org/10.1002/app.1974

Fakhrul-Razi A, Pendashteh A, Abdullah LC, et al (2009) Review of technologies for oil and gas produced water treatment. J Hazard Mater 170:530-551 
748

Fu Y, Li G, Yu H, Liu Y (2012) Hydrophobic modification of wood via surface-initiated ARGET ATRP of MMA. Appl Surf Sci 258:2529-2533

Galhardo L, Tienne P, Vermelha P, Janeiro R De (2018) Poly ( Methyl Methacrylate ) -SiC Nanocomposites Prepared Through in Situ Polymerization 2 . Materials and Methods. 21:

Guettler BE, Moresoli C, Simon LC (2013) Contact angle and surface energy analysis of soy materials subjected to potassium permanganate and autoclave treatment. Ind Crops Prod 50:219-226. https://doi.org/10.1016/j.indcrop.2013.06.035

Hollick EJ, Spalton DJ, Ursell PG, Pande M V Biocompatibility of poly ( methyl methacrylate ), silicone, and AcrySof intraocular lenses : Randomized comparison of the cellular reaction on the anterior lens surface. J Cataract Refract Surg 24:361-366. https://doi.org/10.1016/S0886-3350(98)80324-6

Huang C, Tassone T, Woodberry K, et al (2009) Impact of ATRP initiator spacer length on grafting poly (methyl methacrylate) from silica nanoparticles. Langmuir 25:13351-13360

Husseien M, Amer AA, El-Maghraby A, Taha NA (2009) Availability of barley straw application on oil spill clean up. Int J Environ Sci Technol 6:123-130

Ibrahim S, Ang H, Wang S (2012) Adsorptive separation of emulsified oil in wastewater using biosorbents. Asia-Pacific J Chem Eng 7:S216-S221

Ibrahim S, Ang HM, Wang S (2009) Removal of emulsified food and mineral oils from wastewater using surfactant modified barley straw. Bioresour Technol 100:5744-5749. https://doi.org/10.1016/j.biortech.2009.06.070

Jiang Y, Lawrence M, Ansell MP, Hussain A (2018) Cell wall microstructure, pore size distribution and absolute density of hemp shiv. R Soc Open Sci 5:. https://doi.org/10.1098/rsos.171945

Kim DW, Shin J, Choi SQ (2020) Nano-dispersed cellulose nanofibrils-PMMA composite from pickering emulsion with tunable interfacial tensions. Carbohydr Polym 247:116762. https://doi.org/10.1016/j.carbpol.2020.116762

Lee HM, An KH, Kim BJ (2014) Effects of carbonization temperature on pore development in polyacrylonitrile-based activated carbon nanofibers. Carbon Lett 15:146-150. https://doi.org/10.5714/CL.2014.15.2.146

Li D, Zhu FZ, Li JY, et al (2013) Preparation and characterization of cellulose fibers from corn straw as natural oil sorbents. Ind Eng Chem Res 52:516-524 
Li Y, Wang M, Sun D, et al (2018) Applied Clay Science E ff ective removal of emulsi fi ed oil from oily wastewater using surfactant- modi fi ed sepiolite. 157:227-236. https://doi.org/10.1016/j.clay.2018.02.014

Lin KYA, Chen SY (2015) Enhanced removal of oil droplets from oil-in-water emulsions using polyethylenimine-modified rice husk. Waste and Biomass Valorization 6:495-505.

Liu R, Yu H, Huang Y (2005) Structure and morphology of cellulose in wheat straw. Cellulose 12:25-34. https://doi.org/10.1007/s10570-004-0955-8 https://doi.org/10.1007/s12649-015-9384-1 Lv E, Xia W, Tang M, Pu Y (2017) Preparation of an Efficient Oil-Spill Adsorbent Based on Wheat Straw. BioResources 12:296-315

Maiti S, Sain S, Ray D, Mitra D (2013) Biodegradation behaviour of PMMA / cellulose nanocomposites prepared by in-situ polymerization and ex-situ dispersion methods. Polym Degrad Stab 98:635-642. https://doi.org/10.1016/j.polymdegradstab.2012.11.011

Monson PA (2012) Understanding adsorption/desorption hysteresis for fluids in mesoporous materials using simple molecular models and classical density functional theory. Microporous Mesoporous Mater 160:47-66. https://doi.org/10.1016/j.micromeso.2012.04.043

Mukherjee A, Halder S, Datta D, et al (2017) Free radical induced grafting of acrylonitrile on pre-treated rice straw for enhancing its durability and flame retardancy. J Adv Res 8:73-83. https://doi.org/10.1016/j.jare.2016.12.003

Mysore D, Viraraghavan T, Jin YC (2005) Treatment of oily waters using vermiculite. Water Res 39:2643-2653. https://doi.org/10.1016/j.watres.2005.04.034

nan Shen J, chao Yu C, min Ruan H, et al (2013) Preparation and characterization of thin-film nanocomposite membranes embedded with poly (methyl methacrylate) hydrophobic modified multiwalled carbon nanotubes by interfacial polymerization. J Memb Sci 442:1826

Okiel K, El-Sayed M, El-Kady MY (2011) Treatment of oil-water emulsions by adsorption onto activated carbon, bentonite and deposited carbon. Egypt J Pet 20:9-15. https://doi.org/10.1016/j.ejpe.2011.06.002

Ongarbayev $\tilde{\mathrm{A}} \square \hat{A} \bullet K$ KK (2015) Oil Sorption by Heat-Treated Rice Husks. J Pet Environ Biotechnol 06:10-12. https://doi.org/10.4172/2157-7463.1000243 
810 Pampanin DM, Sydnes MO Polycyclic Aromatic Hydrocarbons a Constituent of Petroleum :

811 Presence and Influence in the Aquatic Environment

812 Pintor AMA, Vilar VJP, Botelho CMS, Boaventura RAR (2016) Oil and grease removal from

813 wastewaters: sorption treatment as an alternative to state-of-the-art technologies. A critical

814 review. Chem Eng J 297:229-255

815 Quach NKN, Yang WD, Chung ZJ, Tran HL (2017) The Influence of the Activation

816 Temperature on the Structural Properties of the Activated Carbon Xerogels and Their

817 Electrochemical Performance. Adv Mater Sci Eng 2017:.

818 https://doi.org/10.1155/2017/8308612

819 Ratcha A, Samart C, Yoosuk B, et al (2015) Polyisoprene modified poly (alkyl acrylate) foam as

820 oil sorbent material. J Appl Polym Sci 132:

821 Ratcha A, Yoosuk B, Kongparakul S (2014) Grafted methyl methacrylate and butyl methacrylate

822 onto natural rubber foam for oil sorbent. In: Advanced Materials Research. Trans Tech

823 Publ, pp 385-390

824 Rosli NA, Ahmad I, Abdullah I, et al (2015) Hydrophobic modification of cellulose isolated

825 from Agave angustifolia fibre by graft copolymerisation using methyl methacrylate.

826 Carbohydr Polym 125:69-75

827 Russell KE (2002) Free radical graft polymerization and copolymerization at higher

828 temperatures. Prog Polym Sci 27:1007-1038. https://doi.org/10.1016/S0079-

$829 \quad 6700(02) 00007-2$

830 Sabir S (2015) Approach of cost-effective adsorbents for oil removal from oily water. Crit Rev

831 Environ Sci Technol 45:1916-1945

832 Samal RK, Sahoo PK, Samantaray HS (1986) Graft Copolymerization of Cellulose, Cellulose

833 Derivatives, and Lignocellulose. J Macromol Sci Part C 26:81-141.

834 https://doi.org/10.1080/07366578608081970

835 Singha AS, Rana AK (2012) Preparation and characterization of graft copolymerized Cannabis

836 indica L. fiber-reinforced unsaturated polyester matrix-based biocomposites. J Reinf Plast

837 Compos 31:1538-1553. https://doi.org/10.1177/0731684412442989

838 Sokker HH, El-Sawy NM, Hassan MA, El-Anadouli BE (2011) Adsorption of crude oil from

839 aqueous solution by hydrogel of chitosan based polyacrylamide prepared by radiation

840 induced graft polymerization. J Hazard Mater 190:359-365. 
https://doi.org/10.1016/j.jhazmat.2011.03.055

842 Soleimani E, Moghaddami R (2018) Synthesis, characterization and thermal properties of PMMA/CuO polymeric nanocomposites. J Mater Sci Mater Electron 29:4842-4854

844 Sugumaran D, Juhanni K, Karim A (2017) Removal of Copper (II) Ion Using Chitosan-Graft845 Poly (Methyl Methacrylate) as Adsorbent. eProceedings Chem 2:1-11

846 Sun R, Sun X, Sun J, Zhu Q (2004) Effect of tertiary amine catalysts on the acetylation of wheat 847 straw for the production of oil sorption-active materials. Comptes Rendus Chim 7:125-134

848 Sun XF, Sun R, Sun JX (2002) Acetylation of rice straw with or without catalysts and its characterization as a natural sorbent in oil spill cleanup. J Agric Food Chem 50:6428-6433. https://doi.org/10.1021/jf020392o

Tan X, Wang H-MD, Zang D, et al (2021) Superhydrophobic/superoleophilic corn straw as an eco-friendly oil sorbent for the removal of spilled oil. Clean Technol Environ Policy 23:145-152

Tang M, Zhang R, Pu Y (2018) Wheat straw modified with palmitic acid as an efficient oil spill adsorbent. Fibers Polym 19:949-955

Thakur VK, Thakur MK, Gupta RK (2013a) Graft Copolymers from Natural Polymers Using Free Radical Polymerization. Int. J. Polym. Anal. Charact. 18:495-503

Thakur VK, Thakur MK, Gupta RK (2013b) Synthesis of lignocellulosic polymer with improved chemical resistance through free radical polymerization. Int J Biol Macromol 61:121-126. https://doi.org/10.1016/j.ijbiomac.2013.06.045

Thommes M, Kaneko K, Neimark A V., et al (2015) Physisorption of gases, with special reference to the evaluation of surface area and pore size distribution (IUPAC Technical Report). Pure Appl Chem 87:1051-1069. https://doi.org/10.1515/pac-2014-1117

Thomsen ST, Weiss ND, Zhang H, Felby C (2021) Water retention value predicts biomass recalcitrance for pretreated biomass: biomass water interactions vary based on pretreatment chemistry and reflect composition. Cellulose 28:317-330. https://doi.org/10.1007/s10570020-03507-w

Tosh B, Routray CR (2014) Grafting of cellulose based materials : a review. Chem Sci Rev Lett 3:74-92

Wahi R, Chuah Abdullah L, Nourouzi Mobarekeh M, et al (2017) Utilization of esterified sago bark fibre waste for removal of oil from palm oil mill effluent. J Environ Chem Eng 5:170- 
177. https://doi.org/10.1016/j.jece.2016.11.038

873 Wang H, Kumar R, Memon H (2020) Strongly Hydrophobic and Superoleophilic PMMA Based Nanocoated Cotton Fabrics. Coatings 10:943

875 Wang J, Zheng Y, Wang A (2012) Superhydrophobic kapok fiber oil-absorbent: Preparation and 876 high oil absorbency. Chem Eng J 213:1-7

877 Wang Y, Zhang X, Yan J, et al (2011) Surface modification of hydroxyapatite with poly (methyl 878 methacrylate) via surface-initiated ATRP. Appl Surf Sci 257:6233-6238

879 Wenzel RN (1949) Surface Roughness and Contact Angle. J Phys Colloid Chem 53:1466-1467. https://doi.org/10.1021/j150474a015

Williams DL, Ong RG, Mullet JE, Hodge DB (2019) Integration of Pretreatment With Simultaneous Counter-Current Extraction of Energy Sorghum for High-Titer Mixed Sugar Production. Front Energy Res 6:. https://doi.org/10.3389/fenrg.2018.00133

Xavier ALP, Adarme OFH, Furtado LM, et al (2018) Modeling adsorption of copper(II), cobalt(II) and nickel(II) metal ions from aqueous solution onto a new carboxylated sugarcane bagasse. Part II: Optimization of monocomponent fixed-bed column adsorption. J Colloid Interface Sci 516:431-445. https://doi.org/10.1016/j.jcis.2018.01.068

Xu J, Wang L, Zhu Y (2012) Decontamination of bisphenol A from aqueous solution by graphene adsorption. Langmuir 28:8418-8425. https://doi.org/10.1021/la301476p

Xu Y, Yang H, Zang D, et al (2018) Preparation of a new superhydrophobic/superoleophilic corn straw fiber used as an oil absorbent for selective absorption of oil from water. Bioresour Bioprocess 5:. https://doi.org/10.1186/s40643-018-0194-8

Yang C, Chih Y, Cheng H, Chen C (2005) Nanofibers of self-doped polyaniline. 46:1068810698. https://doi.org/10.1016/j.polymer.2005.09.044

Yang L, Wang Z, Li X, et al (2016) Hydrophobic modification of platanus fruit fibers as natural hollow fibrous sorbents for oil spill cleanup. Water, Air, Soil Pollut 227:1-12

Yu H, Liu R, Qiu L, Huang Y (2007) Composition of the cell wall in the stem and leaf sheath of 901 Zamparas M, Tzivras D, Dracopoulos V, Ioannides T (2020) Application of Sorbents for Oil

902 Spill Cleanup Focusing on Natural-Based Modified Materials: A Review. Molecules wheat straw. J Appl Polym Sci 104:1236-1240

Yu H, Liu R, Shen D, et al (2008) Arrangement of cellulose microfibrils in the wheat straw cell wall. Carbohydr Polym 72:122-127. https://doi.org/10.1016/j.carbpol.2007.07.035 
904 Zang D, Zhang M, Liu F, Wang C (2016) Superhydrophobic/superoleophilic corn straw fibers as 905 effective oil sorbents for the recovery of spilled oil. J Chem Technol Biotechnol 91:2449_ 906 2456. https://doi.org/10.1002/jctb.4834

907 Zanoletti A, Vassura I, Venturini E, et al (2018) A new porous hybrid material derived from 908 silica fume and alginate for sustainable pollutants reduction. Front Chem 6:1-13. 909 https://doi.org/10.3389/fchem.2018.00060

910 Zhao SX, Ta N, Wang XD (2017) Effect of temperature on the structural and physicochemical 911 properties of biochar with apple tree branches as feedstock material. Energies 10:

912 https://doi.org/10.3390/en10091293

913 